\title{
Secular Crustal Deformation Characteristics Prior to the 2011 Tohoku-Oki Earthquake of Mw 9.1 Detected from IGS Array, 2002-2011
}

Keke Xu

Henan Polytechnic University

Rong He ( $\nabla$ hero@hpu.edu.cn )

Henan Polytechnic University

Kezhao Li

Henan Polytechnic University

Ankang Ren

Henan Polytechnic University

Siyuan Jiang

Henan Polytechnic University

Full paper

Keywords: GPS observations, Crustal deformation, Spatiotemporal Filtering, Region strain, Tohoku-Oki earthquake of Mw 9.1

Posted Date: January 5th, 2021

DOI: https://doi.org/10.21203/rs.3.rs-137407/v1

License: (c) (1) This work is licensed under a Creative Commons Attribution 4.0 International License.

Read Full License 


\section{Secular Crustal Deformation Characteristics Prior to}

\section{2 the 2011 Tohoku-Oki Earthquake of Mw 9.1}

3 Detected from IGS Array, 2002-2011

$4 \quad$ Keke $\mathrm{Xu}^{1,2 *}$, Rong $\mathrm{He}^{1 *}$, Kezhao $\mathrm{Li}^{1}$, Ankang Ren ${ }^{1}$, Siyuan Jiang ${ }^{1}$

51 School of Surveying and Land Information Engineering of Henan Polytechnic University,

6 Jiaozuo 454000, China.

72 State Key Laboratory of Earthquake Dynamics, Institute of Geology, China Earthquake

8 Administration, Beijing 100029,China.

9 *Correspondence: xkk@hpu.edu.cn, hero@hpu.edu.cn

\section{Abstract}

12 In order to reveal the secular deformation evolution and strain accumulation

13 progress along subduction zone, we focus on high-precision Global Positioning

14 System (GPS) data processing, GPS time series analysis and regional

15 spatiotemporal filtering. The GPS position time series is modeled as a combination

16 of the long-term plate movements, short-term noise and the frequency-dependent

17 variations and tectonic deformation information. Common Mode Errors (CME) is

18 removed and the deformation signals is then extracted from the residual time

19 series by Principal Component Analysis (PCA). Combing the filtered displacement

20 array and the dynamic regional strain array derived from GPS baseline, a

21 spatiotemporal tectonic evolution map is exhibited obviously. We process IGS time

22 series over the 2002-2011 period in Japan island and reveal the dynamic evolution

23 of crustal deformation along subduction zone. The results show that the regional

24 reference frame transformation by constraining one site location and one stable 
25 GPS baseline direction can further improve the Signal-to-Noise Ratio (SNR) of GPS

26 observations. A integrated analysis combining the baseline length with azimuth

27 change can show the crustal motion feature more comprehensively. The observed

28 behaviors agree well with the simulation experiment results of the rock rupture in

29 the laboratory. We divide the pre-seismic deformation into four stages, the stable

30 linear strain accumulation stage, the formation stage of the local locked area, local

31 decoupling stage, and strain release stage. We also give an appropriate dynamical

32 model for the interplate coupling to explain the observed deformation

33 characteristics. Research result provides some of the observational new evidence

34 for inter-seismic deformation anomaly detection and the medium- to longer-term

35 seismic hazard assessments.

36 Keywords: GPS observations; Crustal deformation; Spatiotemporal Filtering;

37 Region strain; Tohoku-Oki earthquake of $M_{w} 9.1$

\section{Introduction}

Japanese islands are located in the convergence of the Pacific plate, the north American plate, the Philippine plate and the Eurasian plate, where plate tectonic activities is strong, volcanoes and earthquakes is frequent. Different from intra-continental plate earthquakes, the Pacific plate is under the Japan trench (Fig.1). The Pacific plate is subducting westwards beneath the Eurasian plate at a rate of about $80-90 \mathrm{~mm} / \mathrm{yr}$ and the Philippine Sea Plate is subducting beneath 
southwest Japan at about $65 \mathrm{~mm} / \mathrm{yr}$ ( convergence between the Pacific and Okhotsk(or north American) plates forms an EW compressional stress field constraining the tectonic activity of the region(Ohzono et al., 2013). Both shallow and deep source strong earthquakes in this subduction zone are very active. The seismic slip rate in this area and along the adjacent subduction zone to the south is about $1 / 4$ of the plate convergence rate, which has an important implication for the long-term seismic hazard in this area(Kanamori et al., 2006). Contemporary Global Positioning System (GPS) measurements have revealed a significant strain concentration zone in Tohoku region in northeastern Japan(Miura et al., 2004). According to the historical earthquake catalog from Global Centroid Moment Tensors(GCMT), a total of 6 earthquakes of over $M_{\mathrm{w}} 6.9$ have frequently occurred in the region during 2002-2012, including the $M_{\mathrm{w}} 7.0$ in May 2003, the $M_{\mathrm{w}} 7.2$ in August 2005, the $M_{\mathrm{w}} 6.9$ in June 2008 and the $M_{w} 9.1$ in March 2011. The $M_{w} 9.1$ earthquake is the largest earthquake in recorded history and it happened in the subduction zone at the boundary between the Pacific plate and the North American plate(or Okhotsk plate), which is characterize by a thrust mechanism, with the strike $202^{\circ}$, dip $10^{\circ}$, and rake $90^{\circ}$ (Lay et al., 2011). The co-seismic displacements of the seafloor benchmarks associated with the Tohoku-Oki earthquake estimated by the Japan Coast Guard are $22 \mathrm{~m}$ eastward and $10 \mathrm{~m}$ southward(Sato et al., 2011). Intense co-seismic dislocation happened on the seafloor caused a huge tsunami (Shao et al., 2011), resulting in nearly 20,000 dead or missing. A large number of studies have 
69 reported the anomalous earthquake activities in the source area preceding the

70 Tohoku-Oki earthquake(Hasegawa and Yoshida, 2015; Mavrommatis et al., 2014;

71 Miyazaki et al., 2011; Ozawa et al., 2012; Uchida and Matsuzawa, 2013). A transient

72 slow deformation, which occurred over 7 days in November 2008, was measured

73 using ocean-bottom pressure gauges and an on-shore volumetric strain meter

74 simultaneously. This deformation has been interpreted as a $M_{\mathrm{w}} 6.8$ slow-slip

75 event(SSE) with a slip magnitude of $0.4 \mathrm{~m}$ at most. The other was observed in

76 mid-February 2011, just before the 2011 Tohoku-Oki earthquake of $M_{w}$ 9.1(Ito et al.,

77 2013). These achievements greatly improve our understanding of the nucleation

78 and mitigation processes of earthquakes in subduction zones. However, the

79 earthquake preparation is a long-term process, it is particularly important to know

80 the details of what occurred overall in the source area in a long time prior to this

81 great megathrust earthquake, and reveal the ongoing secular deformations and

82 strain accumulation progress, and improve the medium to longer-term seismic

83 hazard assessments. 


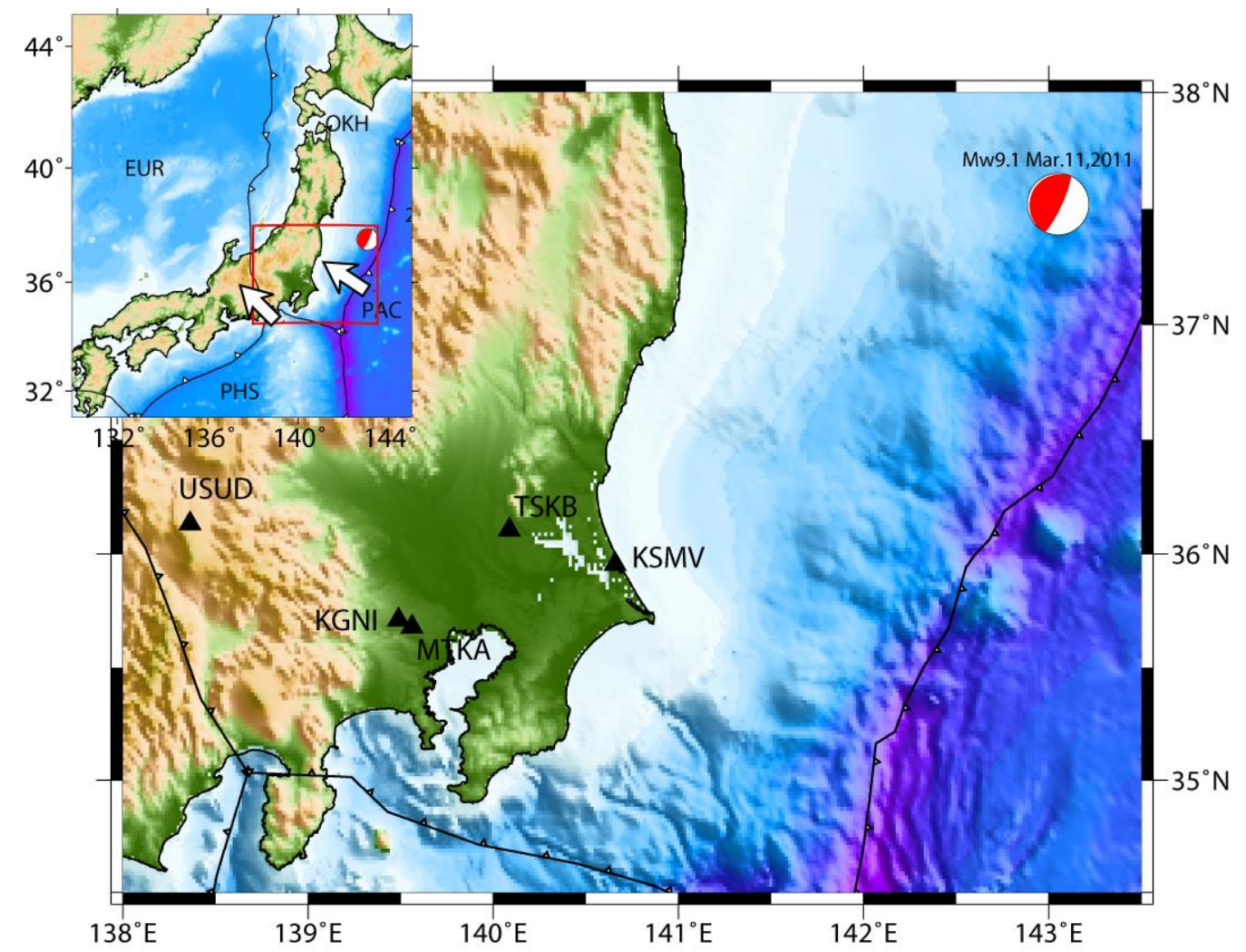

Fig.1. Tectonic settings of the Japanese islands. The study area is depicted in the inset map.EUR, PHS, PAC, and OHK denote Eurasian, Philippine Sea, Pacific and Okhotsk plate, respectively. Beach balls denote GCMT of the earthquake. White arrows indicate the relative plate motion directions. EUR: Eurasian plate, OKH: Okhotsk plate, PHS: Philippine Sea plate, and PAC: Pacific plate.

With high-precision geodetic technology, GNSS observations which record continuously before the mainshock is providing both opportunities and challenges in detection of inter-seismic or pre-seismic deformation signals $(\underline{X u}$ et al., 2020). GNSS networks yield daily estimates of site positions with a high precision of 1-2 $\mathrm{mm}$ in the horizontal and $3-4 \mathrm{~mm}$ in the vertical component over regional distances. However, GNSS observation is complicated by the presence of spatially and temporally coherent noise, Common Mode Errors (CME), local benchmark motion, un-modeled atmospheric delay, reference frame errors and other effects. Therefore, it is almost certain that more subtle signals, due to smaller magnitude events, exist in many observation series already collected but have gone 

progress is obtained, and the details of what occurred overall in the source area in

118 a long time prior to this great megathrust earthquake is revealed. We give an

119 appropriate model for the interplate coupling to explain the observed deformation

undetected. Most observations data used in a previous study were limited to the static deformation field or short-time transient deformation with the larger displacement. Considering that there is a relatively perfect IGS (International GPS Service) continuous observation network distributed on the Japanese islands, it is worth studying whether some crustal deformation information related to the preparation process of this great earthquake can be obtained from GNSS observation array. In this paper, we extend long time GPS array in the source area to investigate long variation in the pre-seismic period, and focus on GPS time series analysis and spatiotemporal filtering to improve GPS Signal-to-Noise Ratio (SNR) and reveal its relevance to the 2011 Tohoku-Oki earthquake of $M_{\mathrm{w}}$ 9.1. Long-term GPS array are used to describe the seismicity process of subduction earthquakes, and the tendency transition of deformation curves in the east coast of Japan island before the earthquake is analyzed. We model the GPS position time series as a combination of the long-term plate movements, short-term noise and the frequency-dependent variations and tectonic deformation information. CME is then removed from the residual time series and the deformation signal is extracted by PCA. Combining the filtered GPS displacement time series with the dynamic strain variation array, the ongoing secular deformations and strain accumulation evolution finally. 
121

122

123

124

125

126

127

128

129

130

131 spatiotemporal filtering. In this paper, the missing data is firstly interpolated by

132 cubic splines function, the time series with abnormally large residuals over 2 root

133 mean square $(\mathrm{RMS})(>2.5,>2.5$, and $>6.5 \mathrm{~mm}$ in north, east, and up directions,

134 respectively) are regarded as outliers. The time series is modeled for removing the

135 trends and seasonal effects. CME is then removed and the deformation signal is

136 extracted from the residual time series by Principal Component Analysis (PCA).

137 The time series of daily GPS site coordinate are fitted as a combination of the

138 annual and semi-annual periodic terms, the initial position and a long-term trend

139 term and the step terms to obtain the residual. The daily time series of the $i$-th

140 coordinate component of the $n$-th GPS station can be modeled as,

$141 \quad y_{n}^{i}(t)=a_{n}^{i}+b_{n}^{i} t+c_{n}^{i} \sin (2 \pi t)+d_{n}^{i} \cos (2 \pi t)+e_{n}^{i} \sin (4 \pi t)+f_{n}^{i} \cos (4 \pi t)+\sum_{k=1}^{m} g_{n, k}^{i} H\left(t-t_{n}^{k}\right)+\varepsilon_{n}^{i}$ 
142 where, $i$ denotes East, North, and Up components, $t$ denotes observed epoch(day).

$143 a, b$ are the initial position and long-term trend of GPS station, respectively. $c$ and $d$ 144 are the sine and cosine amplitudes at annual period, $e$ and $f$ are the sine and cosine 145 amplitudes at semi-annual period, respectively. $H$ is the Heaviside step function, $146 g_{n, k}^{i}$ is a magnitude of the $k$-th step which occurred at $t_{n}^{k}$ due to the earthquakes 147 or replace receiver antenna of subsequent epoch position overall migration. $\varepsilon_{n}^{i}$ is 148 the corresponding noise in the position time series.

149 A time series of daily solution will constitute a lot equations of type (1), so the 150 model coefficients can be estimated by the least-squares criterion. After removing 151 the trend change, seasonal effect and periodic variations, etc., we obtain the 152 residual time series of GPS position.

\subsection{Spatiotemporal Filtering and Signal Extraction}

PCA approach is known as the empirical orthogonal function analysis, which has been widely applied in geodesy, both to filter common mode noise in GPS networks(Dong et al., 2006) and to detect weak regional tectonic deformation

157 signals by improve SNR in GPS coordinate time series(Ji and Herring, 2013;

158 Kositsky and Avouac, 2010; Xu et al., 2015). For GPS residual time series with $n$

159 stations and $m$ days, the matrix $X(m \times n)$ is constructed, and each column denotes

160 the residual value for $\mathrm{N}, \mathrm{E}, \mathrm{U}$ components for each station at all epochs, each rows

161 denotes $\mathrm{N}, \mathrm{E}, \mathrm{U}$ components of all stations at a given epoch. The elements at $i$-th 162 row, $j$-th column of the covariance matrix $B$ is defined as, 


$$
b_{i, j}=\frac{1}{m-1} \sum_{k=1}^{m} x_{k, i} x_{k, j}
$$
unique advantage for the detection of the crustal deformation. We calculate the

where $x_{k, i}, x_{k, j}$ are the elements of $X, i=1,2, \mathrm{~L} m, j=1,2, \mathrm{~L} n$ 。

$$
B(n \times n) \text { is a symmetric matrix, which can be decompose as, }
$$

$$
B=V \Lambda V^{T}
$$

where $\Lambda$ is diagonal matrix with $n$ nonzero eigenvalues. $V$ is orthonormal matrix with $n$ eigenvectors. $X$ can expressed as,

$$
X=A V^{T}, x_{i, j}=\sum_{k=1}^{n} a_{k, i} v_{k, j}
$$

where $a_{k, i}$ is defined as,

$$
a_{k, i}=\sum_{k=1}^{n} x_{i, j} v_{k, j}
$$

where $a_{k}, v_{k}$ is the temporal variations and spatial response of $k$-th principal component of $X$, respectively. The first few PCs usually represent the biggest contributors to the variance of the network residual time series, related to the common source time function. Therefore, CME can be expressed as,

$$
\mathrm{CME}=\sum_{k=1}^{p} a_{k, i} v_{k, j}
$$

where $p$ is the first $p$ PCs.

\subsection{Dynamic Strain Array Calculation}

Strain rate tensor is independent of CME and the reference frame, and have the strain time series based on the high-precision GPS baseline vectors (see Fig.6). 
182

183

184

185

186

187

188

189

190

191

194 195 baseline length is much less than baseline length, that is, baseline, $\cos \alpha=\Delta x / S, \cos \beta=\Delta y / S$. Replacing direction cosine $\alpha, \beta$ with coordinate 201 azimuth $\varphi,(11)$ can thus be written as,

202

Suppose that the plane baseline vector before deformation is $(\Delta x, \Delta y)$ and the length is $S$, the baseline length after deformation is $S^{\prime}$. The infinitesimal element along side length $S$ and $S^{\prime}$ is $d S$ and $d S^{\prime}$, respectively. According to the elastic mechanics theory(Eringen, 1980), the strain tensors of a small element are related with change of a baseline length as ,

$$
d S^{12}-d S^{2}=2 E_{k l}(x, t) d x_{k} d y_{l}
$$

where $E_{k l}$ is the Lagrange strain tensor. Regarding $E_{k l}$ as a constant, we integrate two sides of the equation (7) along the side length respectively and yields the following equation.

$$
S^{12}-S^{2}=2 E_{k l} \Delta x_{k} \Delta x_{l}
$$

where $E_{k l}$ is a symmetry tensor. Thus, (9) can be extended as follows:

$$
S^{12}-S^{2}=2 \Delta x^{2} E_{11}+2 \Delta y^{2} E_{22}+4 \Delta x \Delta y E_{12}
$$

where $E_{11}, E_{12}, E_{22}$ represent three plane strain tensors. Because the change of

$$
S^{\prime}-S=\Delta S<<, S^{\prime}+S \approx 2 S
$$

$$
\text { Combining (9) and (10) yields }
$$

$$
\Delta S / S=\cos ^{2} \alpha E_{11}+\cos ^{2} \beta E_{22}+2 \cos \alpha \cos \beta E_{12}
$$

where $\Delta S / S$ represents the linear strain, $\alpha, \beta$ represent the direction cosine of

$$
\Delta S / S=\sin ^{2} \varphi E_{11}+\cos ^{2} \varphi E_{22}+\sin \varphi \cos \varphi E_{12}
$$




$$
E_{1,2}=\frac{e_{11}+e_{22}}{2} \pm \sqrt{\left(\frac{e_{11}-e_{22}}{2}\right)^{2}+\left(e_{12}\right)^{2}}
$$

$$
\varphi=\frac{1}{2} \operatorname{arctg} \frac{2 E_{12}}{E_{22}-E_{11}}
$$

The maximum surface dilatation $I$, the maximum shear strain $T$ and the firs

211 shear strain $T_{1}$ can be expressed as,

$$
I=E_{1}+E_{2}, \quad T=\frac{1}{2}\left(E_{1}-E_{2}\right), \quad T_{1}=E_{11}-E_{22}
$$

\section{Results}

\subsection{GPS Data Processing Results}

This earthquake is recorded by a available modern GPS observation network

216 (http://geodesy.unr.edu/gsrm.php), unfortunately, most sites whose available time less

217 than 3 years prior to the earthquake in source area. The time scale is extremely lack

218 relative to the earthquake preparation scale, thus not enough to investigate the

219 pre-seismic crustal motion and evolution. Therefore, GPS observation data used in

220 this study are mainly from IGS network with 7 continuous stations observed from

2212002 to 2015. GAMIT/GLOBK 10.4 and QOCA software are used to estimate the 
223 observations from global IGS stations are combined to solve for precise satellite

224 orbits. Dual-frequency phase data are used to compute double-difference 225 ionosphere-free residuals, which are then inverted through a least squares 226 procedure for solving the unknown parameters including single-day positions, 227 satellite orbital elements, phase ambiguity integer numbers, tropospheric delay 228 residuals, etc. Uncertainty of $10 \mathrm{~mm}$ for the carrier beat phase data,30 s of sampling 229 intervals, relax mode for the satellite orbit, the IERS2003 model for earth gravity 230 field, solid tide and pole tide, the FES2004 mode for the global ocean tide, the GMF 231 for troposphere mapping functions, and the parameter of zenith delay is estimated 232 every $2 \mathrm{~h}$.

233 Fig.2 displays the daily position time series IGS permanent sites for North, East,

$234 \mathrm{Up}(\mathrm{N}, \mathrm{E}, \mathrm{U})$ components. Obviously, with the difference of the distance from the 235 seismic source, the influence degree of every site from coseismic effect is different 236 completely. AIRA, the furthest site from the epicenter with about $1300 \mathrm{~km}$, the 237 coseismic displacement is close to zero, with less influence from the earthquake, 238 whereas the stations MIZU and KSMV, about $140 \mathrm{~km}$ and $280 \mathrm{~km}$ from the epicenter, 239 have more significant coseismic effect, with $-1.25 \mathrm{~m}, 2.35 \mathrm{~m},-0.11 \mathrm{~m}$ and $0.06 \mathrm{~m}, 0.71 \mathrm{~m}$, $240-0.26 \mathrm{~m}$ in $\mathrm{N}, \mathrm{E}, \mathrm{U}$ direction, respectively. Comparing with MIZU, the vertical 241 displacement of KSMV is more significant than the horizontal displacement. 

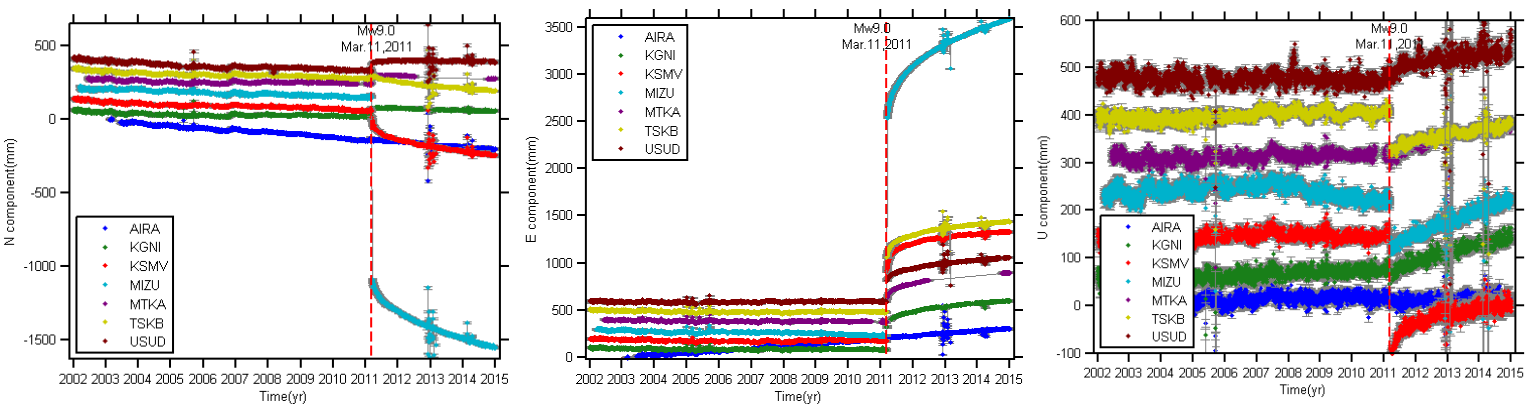

Fig.2. Raw time series of variations in daily site coordinates for the period from 2002 to 2014. The North component, East component and Up components are shown from left to right.

For the sake of better visualization of the pre-seismic deformation features for

the earthquake, we extract the period from Jan. 2002 to Mar. 2011 of GPS

coordinate time series analysis in this study, as shown in Fig.3. The southward

motion of all stations are more significant than the eastward and upward motion in

ITRF2008 reference frame. The several recent earthquakes of over $M_{w} 6.9$ ( e.g., the

$M_{\mathrm{w}} 7.0$ in May 2003, the $M_{\mathrm{w}} 7.2$ in August 2005, the $M_{\mathrm{w}} 6.9$ in June 2008) all occurred

near the station MIZU, far from other sites. Except for MIZU, the co-seismic and

the sites of MIZU and AIRA in following analysis.
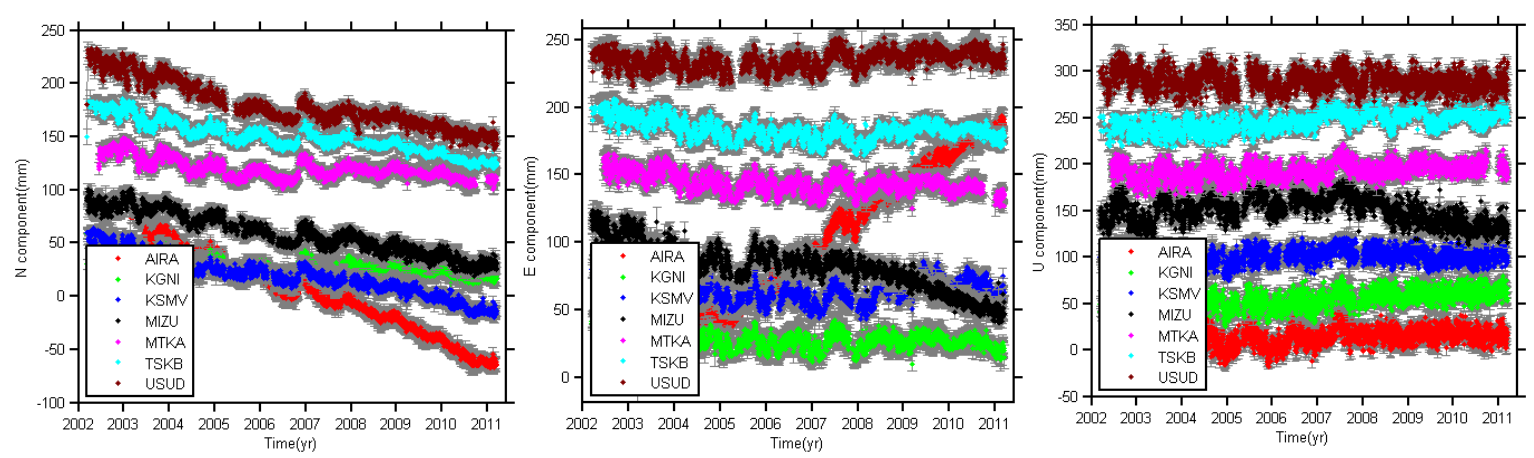

Fig.3. Pre-seismic GPS displacement time series over the period of Feb. 12th, 2002-Mar. 10th, 2011 in $\mathrm{N}, \mathrm{E}, \mathrm{U}$ component from left to right 
We compare the N,E,U coordinate time series derived from double difference model of GAMIT with those obtained by the precise point positioning strategy of as shown in Fig.4. Two solutions from the different algorithms show an overall consistency, indicating the correctness and reliability of the calculated GNSS coordinate array, which can be used for subsequent tectonic deformation extraction and analysis.

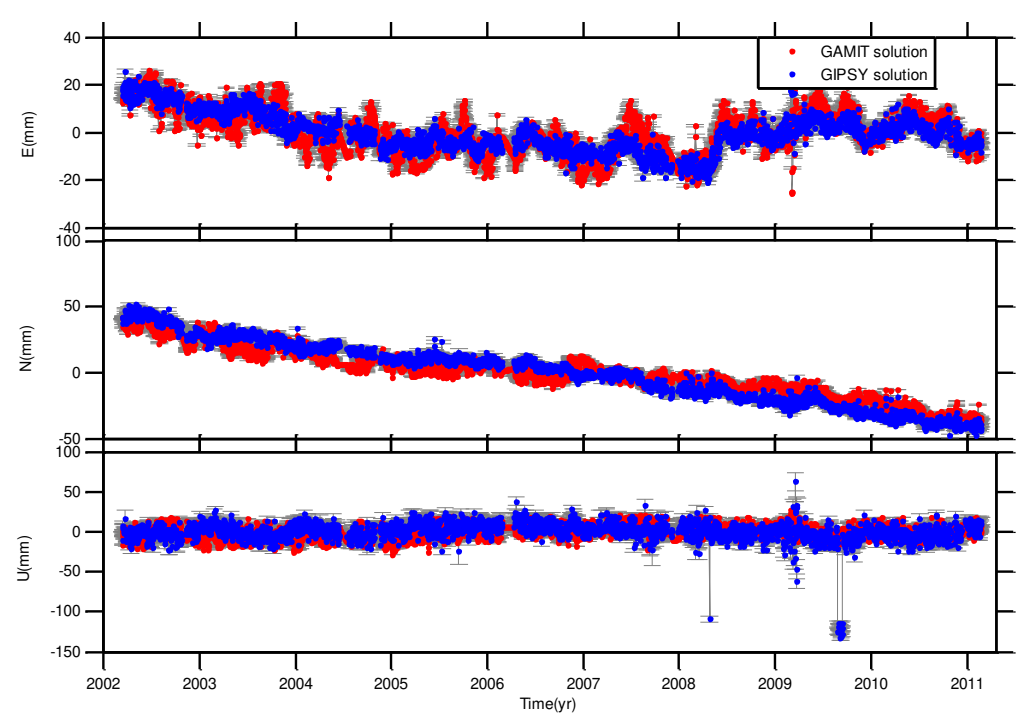
by GAMIT10.4 and GIPSY/OASIS-II.

For the clarity of the internal deformation, we transform the station coordinates from ITRF frame into local reference frame by similarity transformation described by $\underline{X_{u}}$ et al. (2019). Because the movement trends of TSKB and KSMV are extremely similar, with the displacements discrepancies of

272 less than $10 \mathrm{~mm}$ for both $\mathrm{N}$ and $\mathrm{E}$ component over 9 years, we consider TSKB and 273 TSKB-KSMV as the reference point and reference direction, respectively, and perform the similarity transformation for daily solution array of the whole GPS 
275 observation network. The result shows that the SNR of the time series have been 276 greatly improved and the movement details is displayed more obvious( $\underline{\text { Fig.5.5. }}$. In 277 particular, the E displacement time series show a significant arc-like deformation 278 anomaly since 2008, while a stable linear change between 2002-2008.

279

280
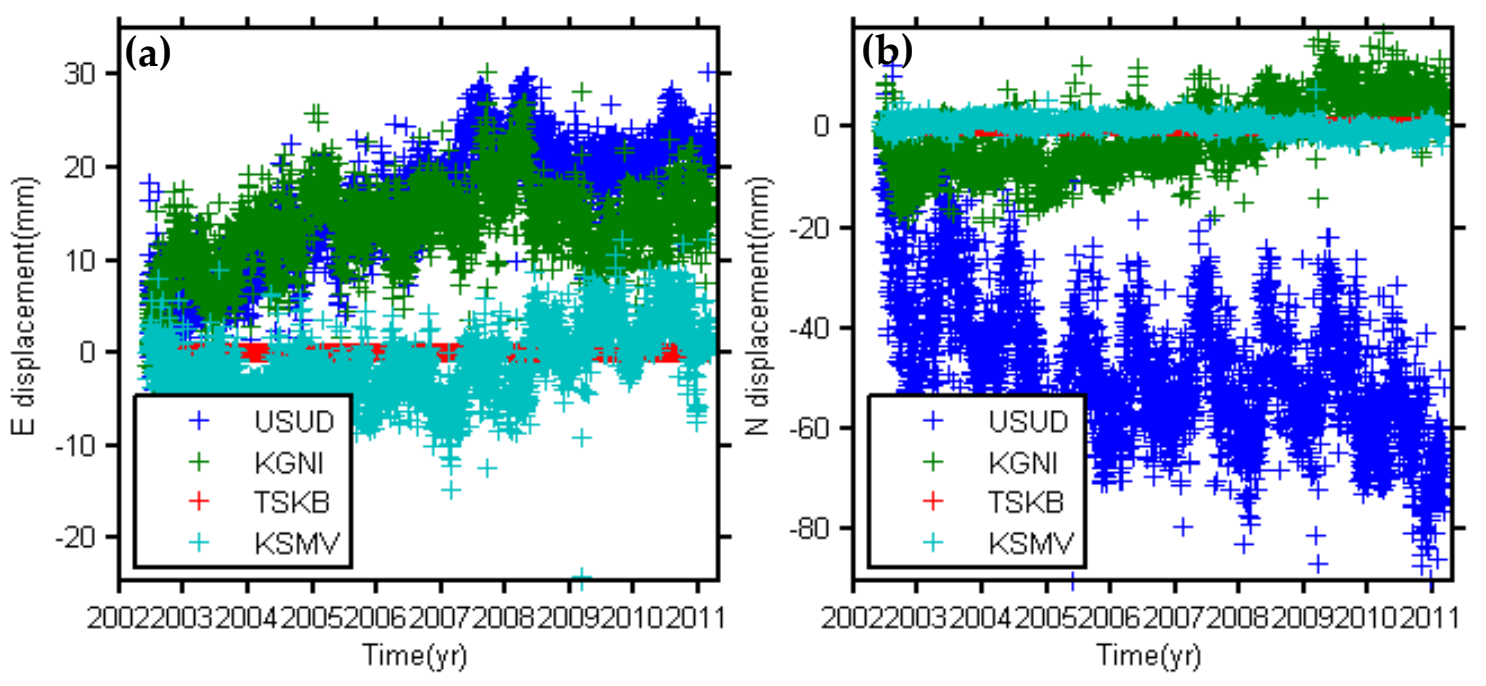

Fig.5. Displacement time series in E component(a) and N component(b) by similarity transformation.

We also constitute GPS baseline network with connecting each site sequentially in near source area. The length and azimuth change time series of all baselines are calculated, as shown in Fig.6. Four baselines reduce linearly between 2002 and 2008, and the longest baseline KSMV-USUD, with the length of $208 \mathrm{~km}$, has the largest contraction rate with about $5 \mathrm{~mm} / \mathrm{y}$. The compression is mainly due to the westward extrusion from of north American plate in NE direction and the Pacific plate in E direction. Obviously, since 2008, all the baseline length variations deviate from the initial linear trends and the compression motion start to slow down and turn to the extension. The baseline azimuth show an abnormal increase process like arc-shaped about during 2005-2008. The anomaly variation of the azimuth 
291 indicates the shear tectonic movement, which probably play the important role in

292 the crustal deformation.
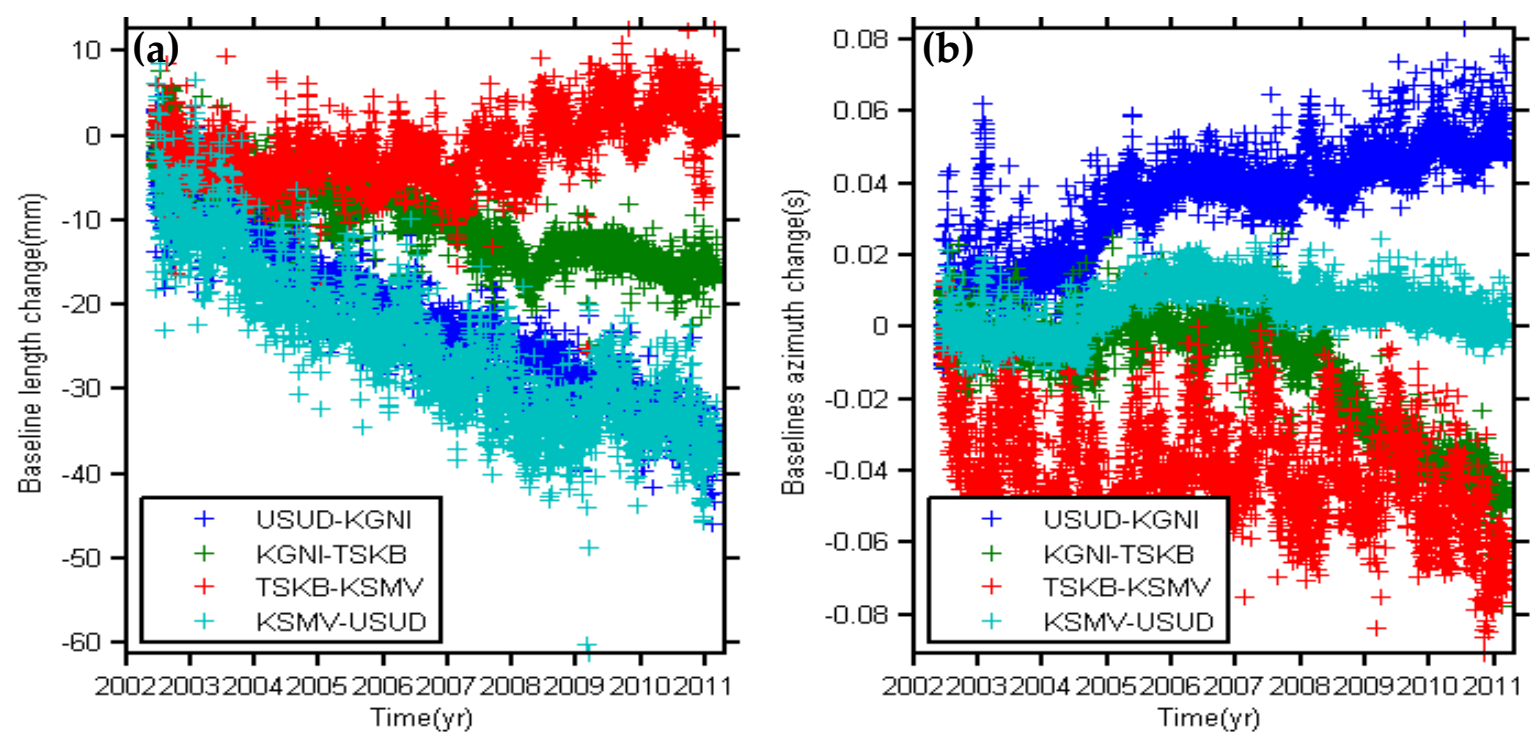

Fig.6. Time series of variations in daily GPS baseline length(a) and azimuth (b) prior to the earthquake.

Fig.7 displays the model fitting result for 4 stations in N,E,U component. The position time series of each station is decomposed into the linear inter-seismic deformation, an annual and an semi-annual cycle periods, and residual time series after removing modeled terms. Obviously, the jumps, discontinuities and the linear trend term have been removed in the residual time series.
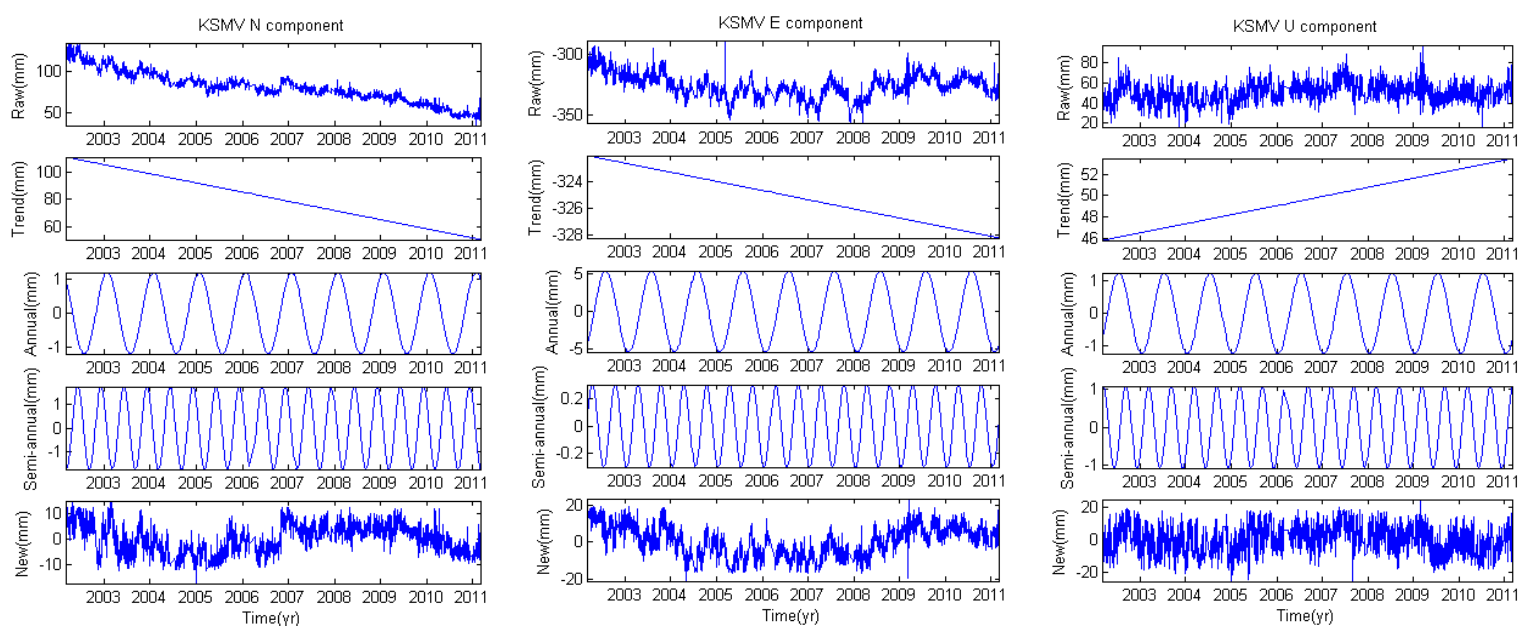







200320042005200620072008200920102011
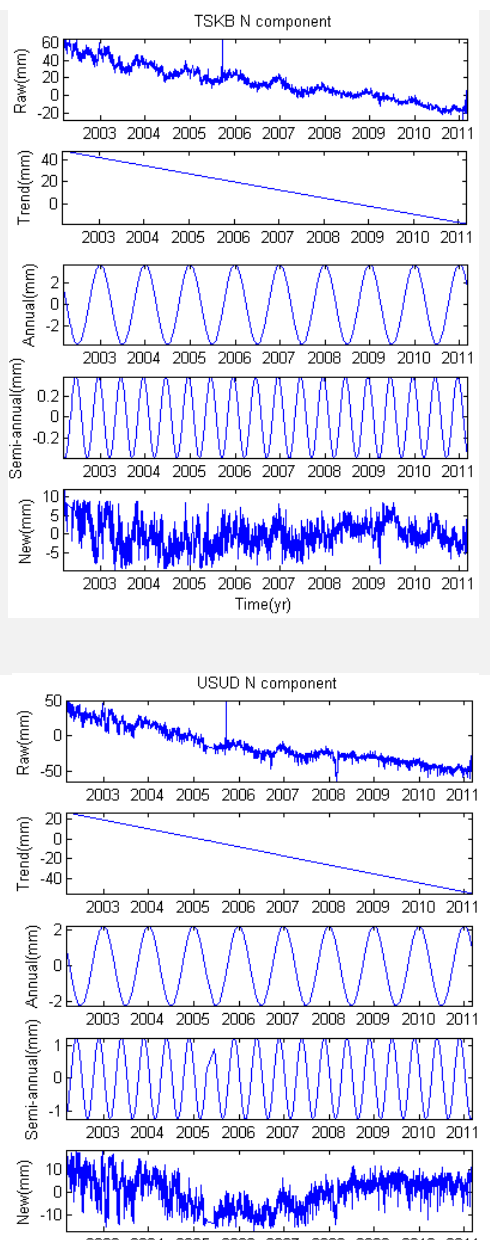

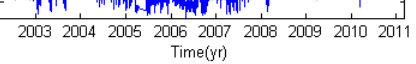


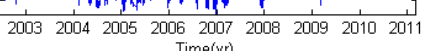

TSKB E component
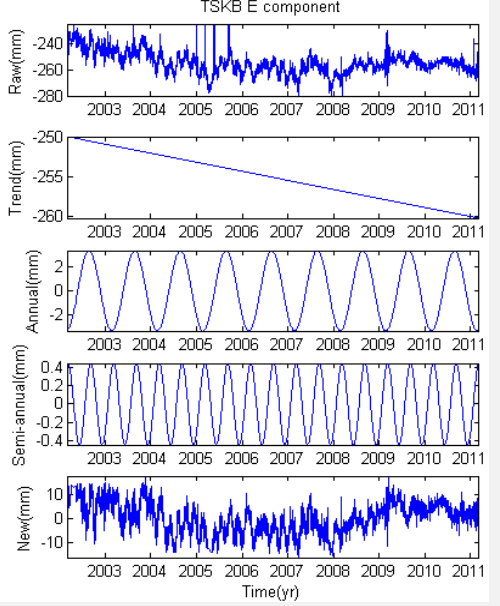

USUD E componen
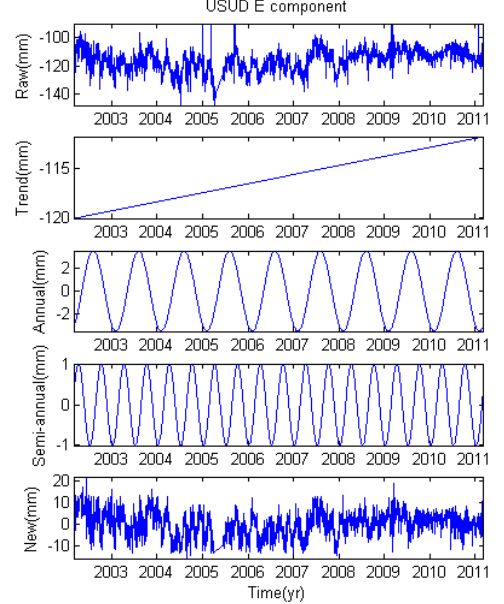
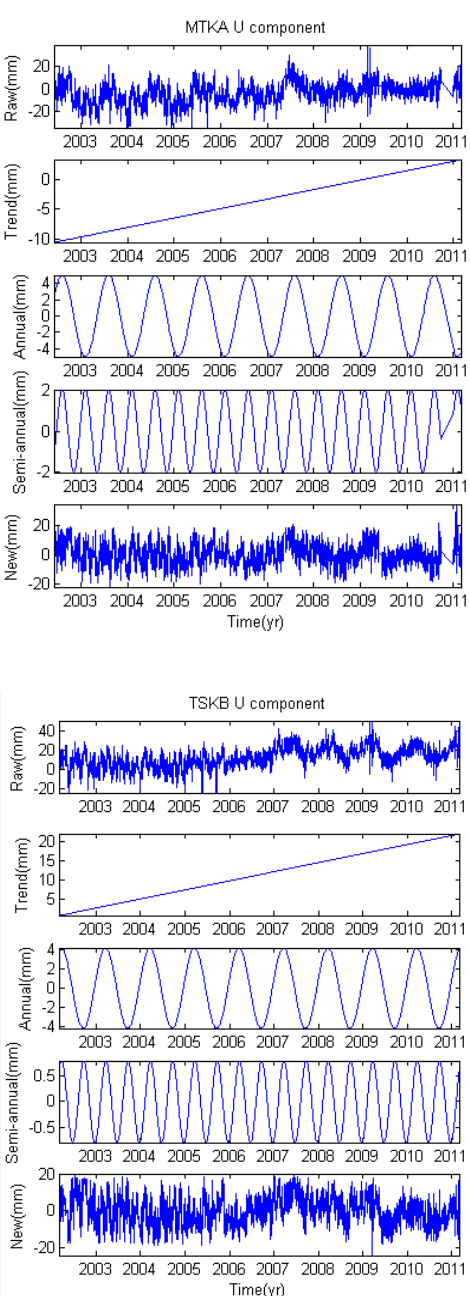
me(yr)


Fig.7. Daily GPS Site Coordinate time series at representative stations, corrected for the secular velocities, seasonal variation and outfield value. The North component, East component and Up components are shown from left to right.

The secular displacement rate is mainly caused by plate movement. In order to 
velocity vectors with respect to the stable Eurasian plate based on the Eurler parameters $\left(55.25^{\circ} \mathrm{N}, 98.3^{\circ} \mathrm{W}, 0.256^{\circ} / \mathrm{Ma}\right)$ from $\mathrm{Xu}$ and $\mathrm{Wu}(2014)$, as shown in Fig.8. average velocity of $20 \mathrm{~mm} / \mathrm{yr}$, due to the subduction of Pacific plate and Philippine significant, with about $1 \mathrm{~mm} / \mathrm{yr}$.

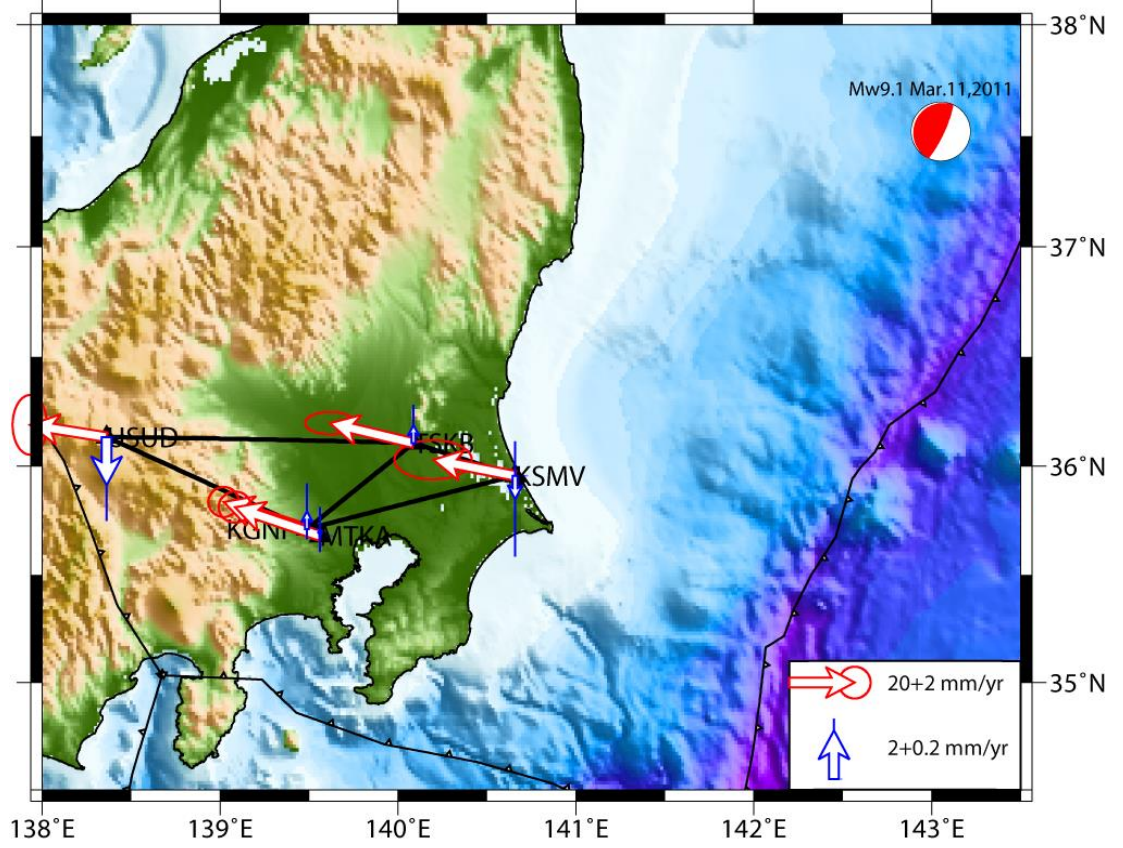

Fig.8. GPS velocity of 5 sites with respect to Eurasian plate. Each velocity arrow originates at the location of the site and points to its motion direction. Error ellipses represent $95 \%$ confidence level.

The residual time series in Fig.7 still show a significant spatial correlation

314 errors among different stations, so the SNR of the GPS residual time series need to

315 be further improved by PCA spatiotemporal filtering. Fig. 9 shows the first 5

316 eigenvalues normalized by the highest one in $\mathrm{N}, \mathrm{E}, \mathrm{U}$ components. The first mode 
317 have significant eigenvalue and other modes are less than $50 \%$ of that of the mode

3181 signal for the $\mathrm{N}, \mathrm{E}, \mathrm{U}$ components.

319

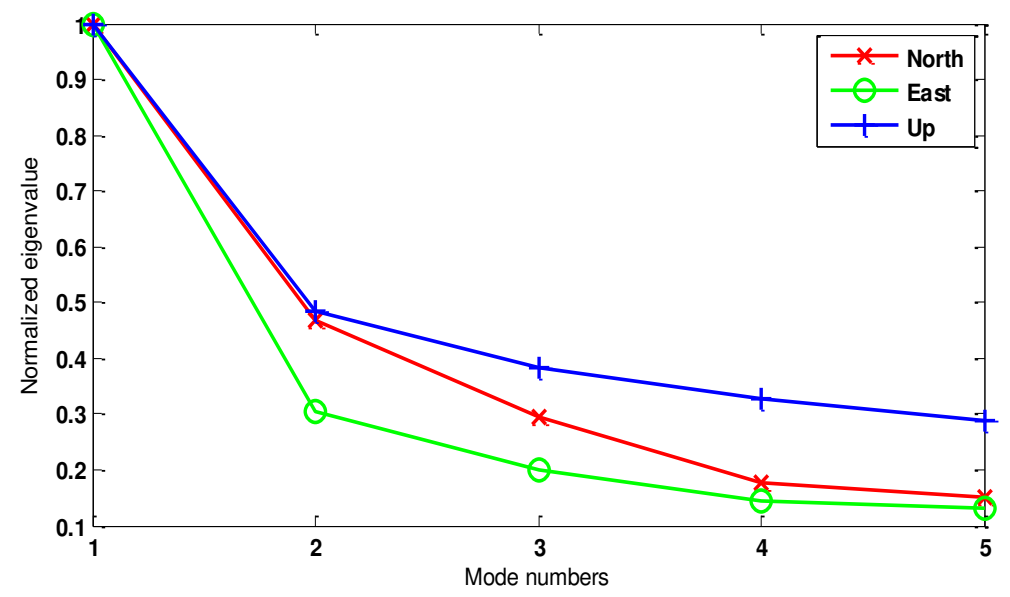

Fig.9. First 5 eigenvalues normalized by the highest one in N, E, U components

Temporal and spatial responses of the first PCs for the east, north, and vertical components by first principle component (PC1) are displayed in Fig.10, Fig.11 and Fig.12, respectively. For all three components, their PC1 in Fig.10, Fig.11 and Fig.12.left show significant responses with spatially uniform distribution, whereas other PCs have no obviously uniform pattern in space or spatial coherence. Although there is no generally accepted consensus on calculation CME at a large scale, for a small GPS network with a spatial scale of $5^{\circ} \times 5^{\circ}$, the mode is considered as CME where most sites (more than 50\%) stations have significant normalized responses with larger than $25 \%$ and the corresponding eigenvalues exceed $1 \%$ of the summation of all eigenvalues (Dong et al., 2006). According to this criterion, we regard the PC1 is regarded as CME, and focus on other modes PCs for tectonic deformation analysis. 

and $\mathrm{U}$ component are shown in Fig.10, Fig.11 and Fig.12.right. For all three components, their temporal variations show the a long-period turning motion process, from westward to eastward, from northward to southward, from upward to downward, respectively. The spatial distribution have the opposite sign in the east and west sides of network. The station KSMV has the most significant spatial responses in three components, which are explained that the station is located on

340 the boundary of ocean-continent, where has the strong impact from subduction.

341 An examination of the third mode's spatiotemporal responses in vertical time 342 series show the similarity to those of the second mode in east and north 343 components. The other mode's temporal variations exhibit the high-frequency 344 irregular fluctuations and the spatial eigenvectors indicates that only a small 345 portion of the stations have modest amplitudes with some significance. Therefore, 346 the PCs of these modes cannot be identified as the potential geophysical processes. 347 They are probably the mixture of unmodeled signals, local effects and noise. The 348 filtered results show a significant temporal variations of turning motion, indicating 349 the motion transition process from compression to tension. The spatial responses 350 denote the spatial distribution features of strain accumulation during the pregnant 351 period of strong earthquake. The western Japan island may still keep stable 352 westward extrusion without gradient change with the region while the east coast 353 of Japan island has strong impact from subduction zone. The opposite spatial 354 distribution in the east and west sides of Japan island probably be explained that 
355 the strain accumulation will release and turn to move in a oppose direction when

356 the deformation reaches the limit.
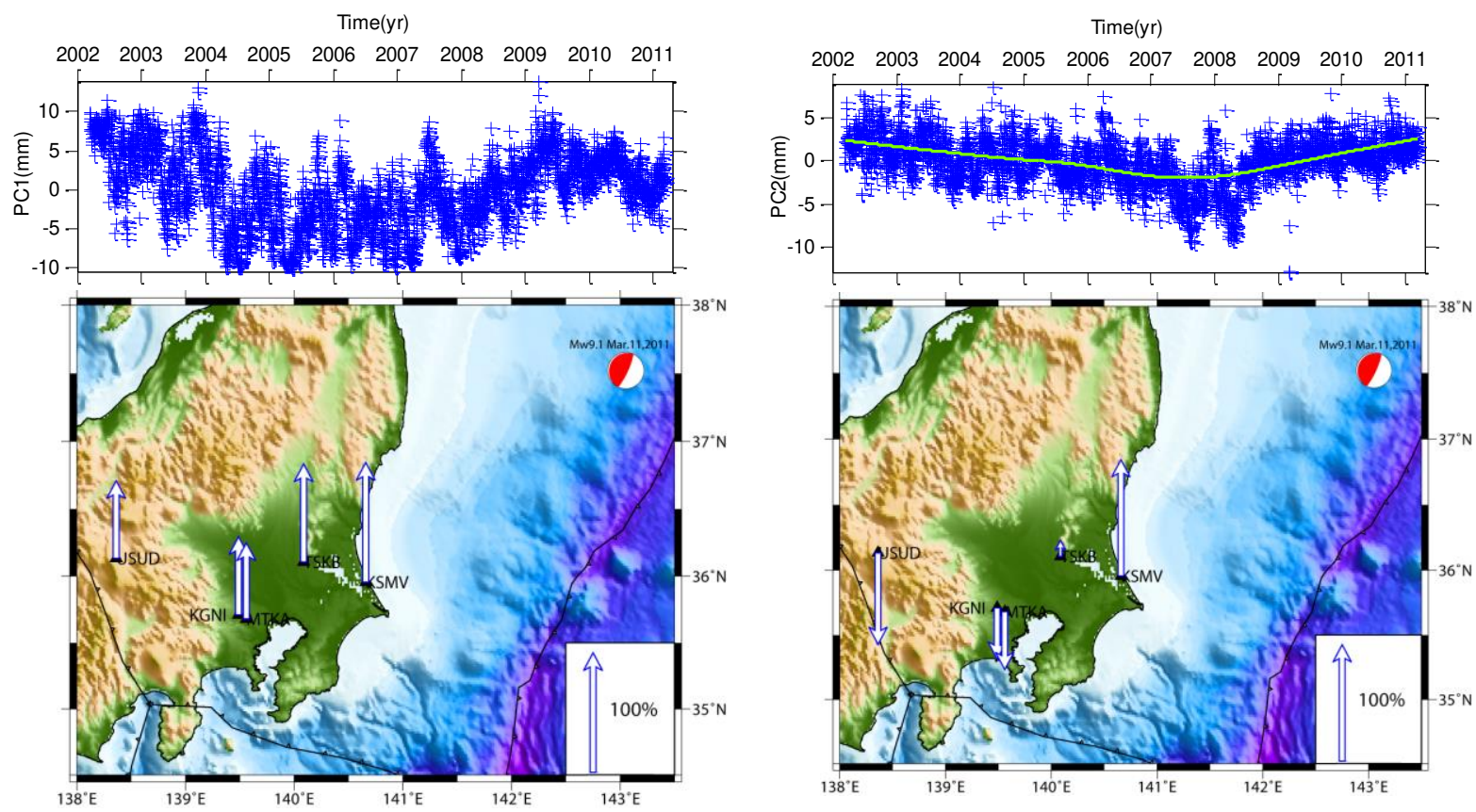

Fig.10. East component of PCA solution. (left) (top) First scaled PC and (bottom) its normalized spatial eigenvectors. The arrows represent the element values of the normalized eigenvectors (not the displacement directions). The upward and downward arrows represent positive and negative responses to the scaled PC, respectively. (right) (top) Second scaled PC and (bottom) its normalized spatial eigenvectors. Solid green curve represent the fit to the data by Gaussian smooth filter.
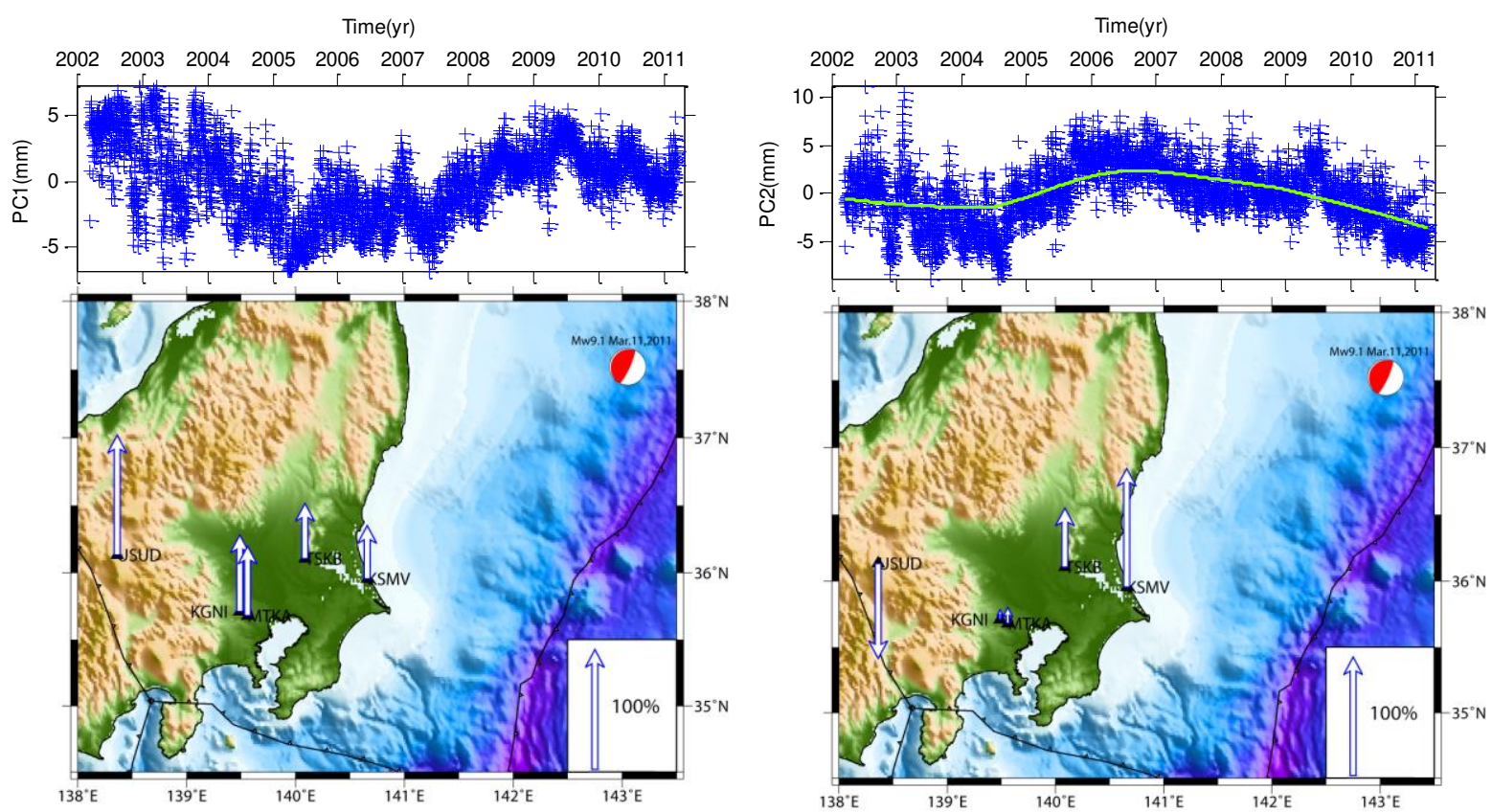

Fig.11. North component of PCA solution. (left) (top) First scaled PC and (bottom) its normalized spatial eigenvectors. (right) (top) Second scaled PC and (bottom) its normalized spatial eigenvectors. The arrows and solid green curve are defined as in Fig.10. 

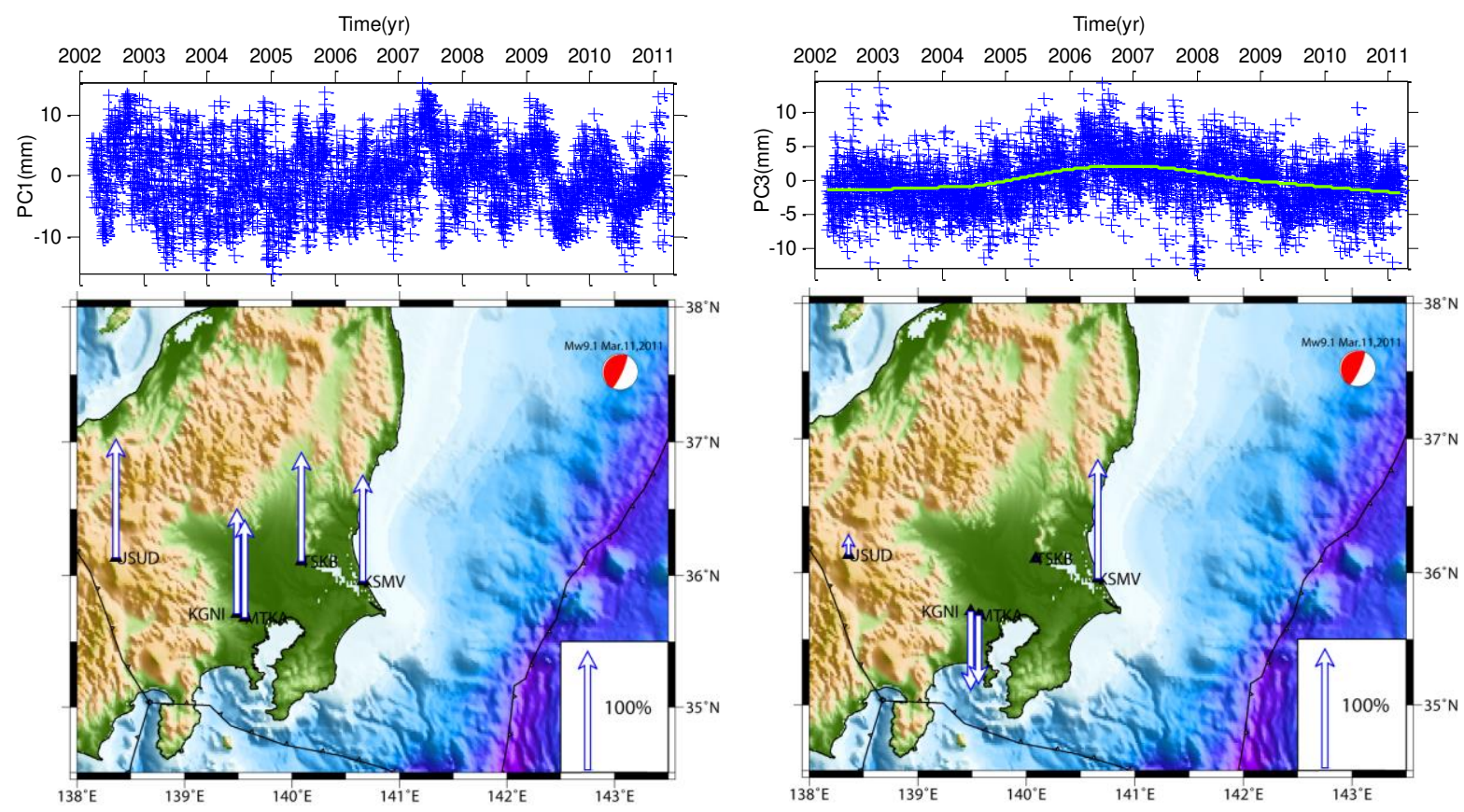

Fig.12. Vertical component of PCA solution. (left) (top) First scaled PC and (bottom) its normalized spatial eigenvectors. (right) (top) Third scaled PC and (bottom) its normalized spatial eigenvectors. The arrows and solid green curve are defined as in Fig.10.

\subsection{Regional Strain Time Series}

Fig.13 displays the maximal shear strain, dilatation strain and the first shear

strain time series of two areas composed of triangles USUD-KGNI-TSKB and

KGNI-KSMV-TSKB (see Fig.8). The dilatation strain time series of all two areas

show a strong compression movement as a whole at the average compression rate

of 67 and 22 nanostrain/yr(10-9/yr), respectively. This is mainly related to eastward

compression resulted from the subduction of Pacific plate and Philippine Sea plate.

364 Comparing with USUD-KGNI-TSKB, the compression of KGNI-KSMV-TSKB show

365 a significant anomalous change process from stably linear strain accumulation to

366 slow down. It probably is because the area of KGNI-KSMV-TSKB is much closer to

367 the subduction belt along Japan trench. The maximal shear strain and the first shear strain in both areas show a transition process from a stable linear change 
status during 2002-2007 to a acceleration increase during 2008-2011. The maximal shear strain have increased significantly from 3 to 26 nanostrain/yr, from 9 to 50 nanostrain/yr for KGNI-KSMV-TSKB and USUD-KGNI-TSKB, respectively. The first shear strain describes the shear deformation of $\mathrm{N} 45^{\circ} \mathrm{W}$ and $\mathrm{N} 45^{\circ} \mathrm{E}$ strike accurately, and the positive value with NE strike denotes the left-lateral shear, therefore, it is inferred that the deformation in the region is mainly characterized by expression and the right-lateral shear motion.
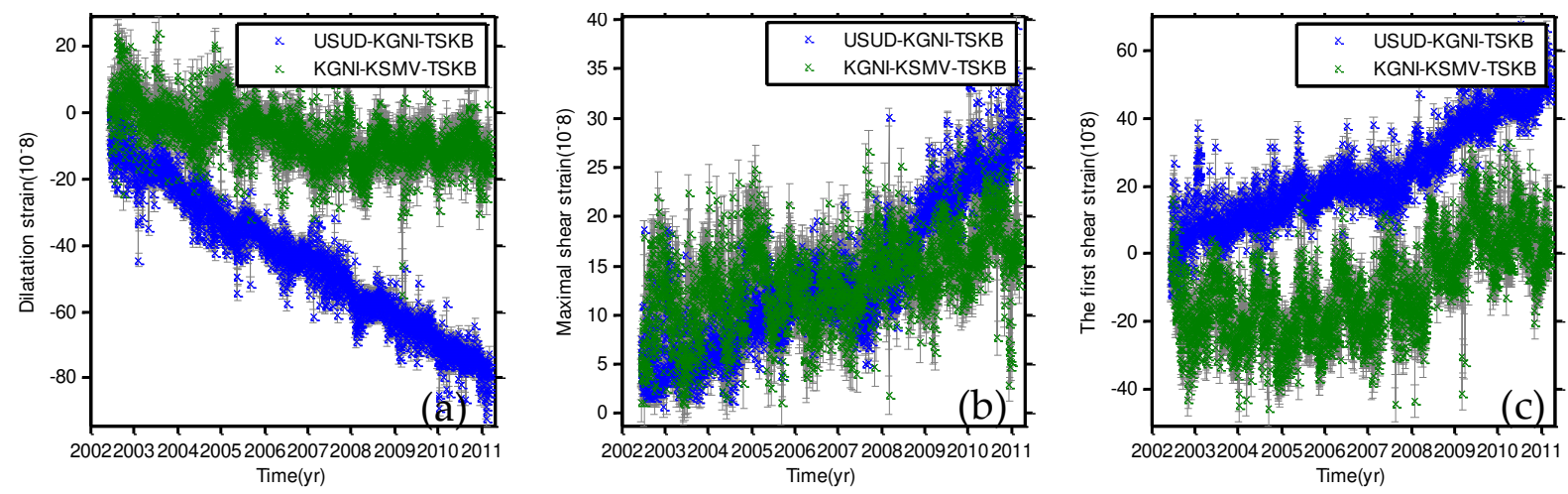

Fig.13. Dilatation strain(a), maximum shear strain(b), and first shear strain array(c) of two regions TSKB-KSMV-MIZU and USUD-TSKB-MIZU drawn in Fig.8.

\section{Discussion}

All the similarity transformation results, baselines array, the filtered displacement time series and the dynamic strain array show a significant pre-seismic deformation anomalies. The dilatation strain time series show a significant change anomaly from stable linear accumulation to slow down. The maximal shear strain and the first shear strain time series show a transition process from a stable linear change status during 2002-2007 to a acceleration change in 2008-2011. The filtered displacement array show a significant evolution process 

have observed and the previous research(Chen et al., 2013; Hoshiba, 2006), we give

406 an model for the interplate coupling to explain the present three-dimensional 407 deformation, as shown in Fig.14. The evolution process is divided into the 408 following four stages.

from the originally stable linear change to the locked status and the reverse motion finally. According to the theory of rock mechanics and deformation, the whole observed behaviors are described as stable linear motion and instable nolinear motion. In first stage, the deformation show a trend of linear increase, referred to as a elastic deformation. The deformation will restore quickly, once the external force is unloaded. In the second stage, the deformation starts to deviate the linear movement trend, both of the elastic and inelastic deformation coexist. Contrary to the first stage, the deformation will not restore completely if the external force is unloaded. In the stage, the strain of different section on subduciton zone begin to appear the features of the differentiation change. The displacement and the dilation strain rate of part of areas decrease gradually, close to the locked status. After a short period of locking, the part locked areas will decouple and appear the reverse motion trend. Meantime, the shear strain transfer to the remaining locked region and become more and more concentrated, resulting in its acceleration accumulation on the whole region, until the occurrence of the earthquake. Our findings are consistent with the simulation experiment results of the rock rupture in the laboratory $(\underline{\mathrm{Ma}, 2016})$.

According to the above spatio-temporal evolution process of crustal motion we anodel for the interplate coupling to explain the present three-dimensional 

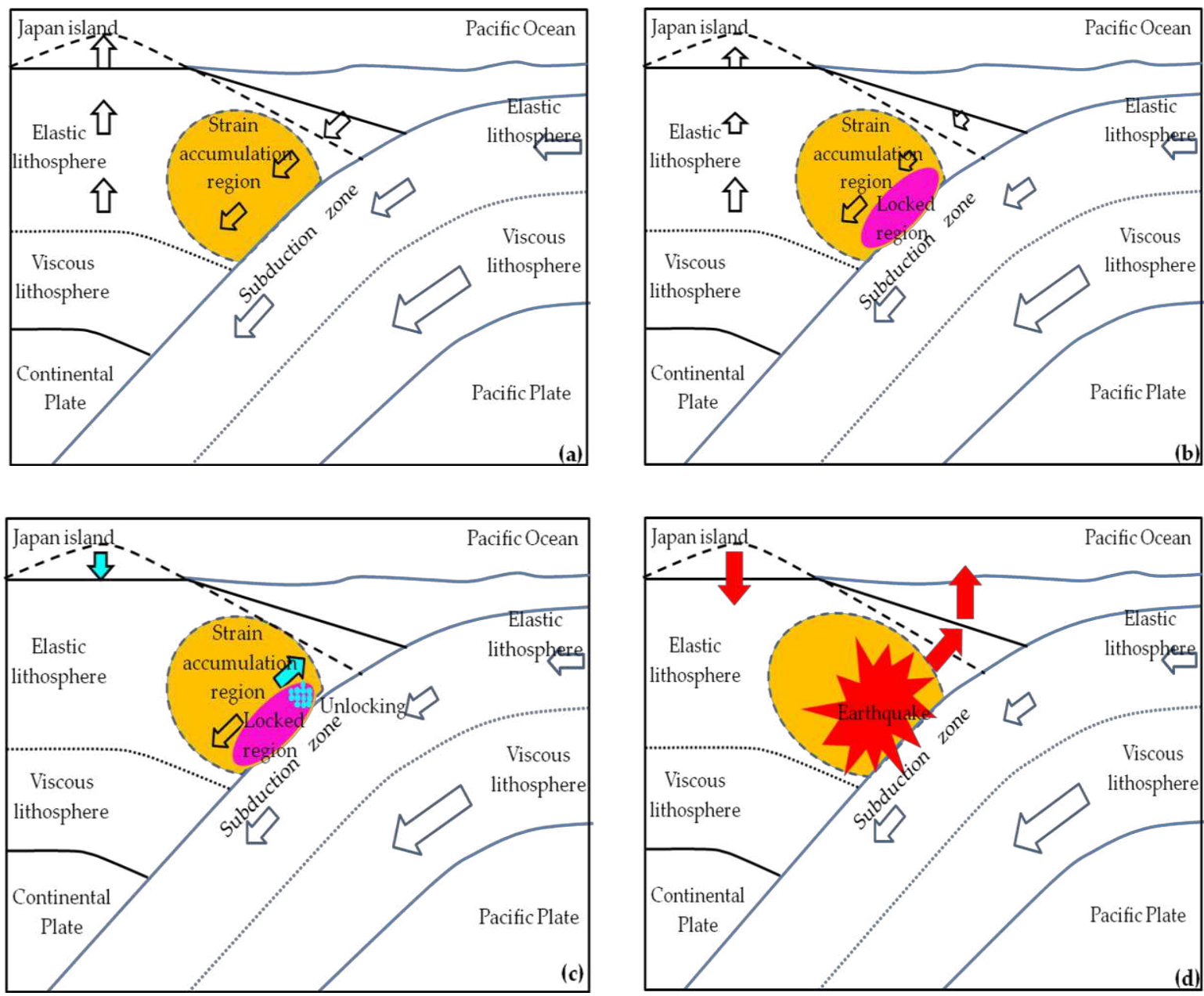

Fig.14. Seismogenic model in plate subduction region.(a) the stable linear strain accumulation stage.(b) the formation stage of the local locked area. (c) local decoupling stage. (d)great rupture and strain release stage(occurrence of great earthquake)

(1) The stable linear strain accumulation stage(ig.14.a). The preliminary linear

413 movement can be explained as the relatively stable motion between two plates in

414 the subduction process of the ocean-continental plate at the beginning of the

415 earthquake preparation. Because the subducting ocean plate is getting stuck, the

416 overriding continental plate will be squeezed and dominated by compression

417 deformation, the leading edges is dragged down, while the hinterland areas in

418 near-field surface is bulged upward. As a result, the strain near the boundary of the

419 plate starts to accumulate, and the seismogenic region is formed initially. 
(2)The formation stage of the local locked area(Fig.14.b). With the continuing

421 of the relative motion between plates in far-field, the frictional stress level gradually

422 increases due to the heterogeneity of the ocean-continental subduction belt contact

423 surface. The ability to resist the deformation gradually reduces, in this case, the

424 deformation deviates from the originally linear trend. The local seismogenesis

425 region presents a deformation characteristic of gradual attenuation from deep to

426 shallow. The westward and upward displacement of the region gradually slows

427 down and reaches the locked state, whereas the remaining regions still keep on

428 relative movement under the action of tectonic stress, so the stress begin to transfer

429 gradually to the locked area and become more and more concentrated.

430

(3) The local decoupling stage(Fig.14.c).The strain accumulation and the stress

431 level in the locked region continuingly increases and reaches the limit finally. The

432 seismological element is decoupled to become the slip area, the part strain energy

433 begins to release slowly, and the surface deformation then appears the reverse

434 motion. In this stage, there is usually pre-slip and increased small earthquake

435 activity. However, the shear strain energy still keep continuing accumulation

436 during locked status. The remaining major locked area get the further concentration

437 of strain and redistribution of stress, resulting in the accelerated accumulation of

438 the shear strain and increasingly high stress concentration degree.

(4) The great rupture and strain release stage (occurrence of great earthquake)

440 (Fig.14.d). With more and more concentrated stress and strain accumulation in the 441 remaining locked area, the frictional resistance between plates is overcome 
442 completely. As a result, the widely distributed locked zones become instable and

443 appear the instantaneous mutation and a large strain release, the elastic rebound 444 happen on the leading edge of the jammed overriding plate, where the obduction 445 and upheaval cause the tsunami phenomenon, while the bulge behind the leading 446 edge is collapsed.

447 In the different stages, the deformation characteristics and the time experienced 448 are different. After four stages of evolution, the whole seismic process is completed.

\section{Conclusions}

The SNR in coordinate time series for regional GPS networks can be further improved by spatiotemporal filtering from the residual GPS observation array. Integrating filtered displacement time series, regional strain, baseline change and processing of similarity transformation, the significant pre-seismic deformation evolution around a period is detected prior to 2011 Tohoku-Oki earthquake of $M_{w}$ gradually, close to the locked status, then reverse motion, instead, the shear strain is more and more concentrated, resulting in the acceleration accumulation. The

458 tectonic evolution for earthquake occurrence along the subduction zone can be 459 described as four stages, the stable linear strain accumulation stage, the formation 460 stage of the locked area, local decoupling stage and great rupture-strain release 461 stage. The surface deformation characteristics of the different stages is also different, 462 the detection of these stages has certain indicative significance for the identification 463 of the surface deformation from destructive earthquakes along the subduction 
zone, which are entirely consistent with the simulation experiment results of the rock rupture in the laboratory. An appropriate model is proposed for well interpreting the observed deformation process. Our findings provide a valuable clue for revealing the seismicity mechanism of subduction earthquakes

\section{Abbreviations}

IGS: International GNSS Service; GPS: Global positioning system; CME: Common Mode Errors; PCA: Principal Component Analysis; RMS: Root Mean Square; SNR : Signal-to-Noise Ratio; N,E,U: North, East, Up

\section{Acknowledgments}

We thank Professor Jicang Wu from Tongii University for the efforts in the effective validation of the strain calculation method. We thank Dr. Weijun Gan from Institute of Geology, China Earthquake Administration for constructive discussions. We are grateful to International GPS Service (IGS) for providing GPS data. GPS data are processed using GAMIT/GLOBK software. Some figures are plotted using the public domain Generic Mapping Tools GMT (Wessel et al., 2013).

\section{Authors' contributions}

Keke $\mathrm{Xu}$ designed the study, performed the methodology research, and drafted the manuscript. Rong He performed data processing and analysis. Kezhao Li performed the validation and assessment of GPS data. Ankang Ren performed and noises analysis of GPS time series and Siyuan Jiang validate the effectiveness of strain results. All authors read and approved the final manuscript.

\section{Funding}

This work was supported by the National Natural Science Foundation of China (No.41774041), Ph. D. Programs Foundation of Henan Polytechnic University(No.B2017-15)

\section{Availability of data and materials}


All datasets and methods during the current study are available from the corresponding author on reasonable request.

\section{Competing interests}

The authors declare that they have no competing interests.

\section{References}

Chen, G.Q., Wu, Y.Q., Jiang, Z.S., Liu, X.X., Zhao, J., 2013. Characteristics of seismogenic model of $\mathrm{M}(\mathrm{W}) 9.0$ earthquake in Tohoku, Japan reflected by GPS data. Chinese Journal of Geophysics 56, 848-856.

Dong, D., Fang, P., Bock, Y., Webb, F., Prawirodirdjo, L., Kedar, S., Jamason, P., 2006. Spatiotemporal filtering using principal component analysis and Karhunen-Loeve expansion approaches for regional GPS network analysis. Journal of Geophysical Research: Solid Earth 111, n/a-n/a.

Eringen, A.C., 1980. Mechanics of continua /2nd edition. Huntington Ny Robert E.krieger Publishing Co.p -1.

Hasegawa, A., Yoshida, K., 2015. Preceding seismic activity and slow slip events in the source area of the $2011 \mathrm{Mw} 9.0$ Tohoku-Oki earthquake: a review. Geoscience Letters.

Heki, K., Miyazaki, S.i., Takahashi, H., Kasahara, M., Kimata, F., Miura, S., Vasilenko, N.F., Ivashchenko, A., An, K.-D., 1999. The Amurian Plate motion and current plate kinematics in eastern Asia. Journal of Geophysical Research: Solid Earth 104, 29147-29155.

Herring, T.A., 2002. GLOBK:Global Kalman filter VLBI and GPS analysis program, version 10.0, Mass. Inst. of Technol., Cambridge.

Hoshiba, M., 2006. Current strategy for prediction of Tokai earthquake and its its recent topics(ppt). .

Ito, Y., Hino, R., Kido, M., Fujimoto, H., Osada, Y., Inazu, D., Ohta, Y., Iinuma, T., Ohzono, M., Miura, S., 2013. Episodic slow slip events in the Japan subduction zone before the 2011 Tohoku-Oki earthquake. Tectonophysics 600, 14-26.

Ji, K.H., Herring, T.A., 2013. Testing Kalman Smoothing/PCA Transient Signal Detection Using Synthetic Data. Seismological Research Letters 84, 433-443.

Kanamori, H., Miyazawa, M., Mori, J., 2006. Investigation of the earthquake sequence off Miyagi prefecture with historical seismograms. Earth Planets \& Space 58, 1533-1541.

King, B.R.W., Bock, Y., 1999. Documentation for the GAMIT GPS analysis software, Mass. Inst. of Technol, Igs Technical Reports.

Kositsky, A.P., Avouac, J.-P., 2010. Inverting geodetic time series with a principal component analysis-based inversion method. Journal of Geophysical Research 115, B03401.

Lay, T., Ammon, C.J., Kanamori, H., Xue, L., Kim, M.J., 2011. Possible large near-trench slip during the 2011 M w 9.0 off the Pacific coast of Tohoku Earthquake. Earth, Planets and 

Space 63, 687-692.

Ma, J., 2016. On "whether earthquake precursors help for prediction do exist". Chinese Science Bulletin 61, 409.

Mavrommatis, A.P., Segall, P., Johnson, K.M., 2014. A decadal-scale deformation transient prior to the 2011Mw9.0 Tohoku-oki earthquake. Geophysical Research Letters 41, 4486-4494.

Miura, S., Sato, T., Hasegawa, A., Suwa..., Y., 2004. Strain concentration zone along the volcanic front derived by GPS observations in NE Japan arc. Earth Planets \& Space 56, 1347-1355.

Miyazaki, S.i., McGuire, J.J., Segall, P., 2011. Seismic and aseismic fault slip before and during the 2011 off the Pacific coast of Tohoku Earthquake. Earth, Planets and Space 63, 637-642.

Ohzono, M., Yabe, Y., Iinuma, T., Ohta, Y., Miura, S., Tachibana, K., Sato, T., Demachi, T., 2013. Strain anomalies induced by the 2011 Tohoku Earthquake ( $\mathrm{Mw} 9.0$ ) as observed by a dense GPS network in northeastern Japan. Earth, Planets and Space 64, 1231-1238.

Ozawa, S., Nishimura, T., Munekane, H., Suito, H., Kobayashi, T., Tobita, M., Imakiire, T., 2012. Preceding, coseismic, and postseismic slips of the 2011 Tohoku earthquake, Japan. Journal of Geophysical Research: Solid Earth 117, n/a-n/a.

Sato, M., Ishikawa, T., Ujihara, N., Yoshida, S., Fujita, M., Mochizuki, M., Asada, A., 2011. Displacement Above the Hypocenter of the 2011 Tohoku-Oki Earthquake. Science 332, 1395-1395.

Shao, G., Li, X., Ji, C., Maeda, T., 2011. Focal mechanism and slip history of the $2011 \mathrm{M} \mathrm{w} 9.1$ off the Pacific coast of Tohoku Earthquake, constrained with teleseismic body and surface waves. Earth, Planets and Space 63, 559-564.

Uchida, N., Matsuzawa, T., 2013. Pre- and postseismic slow slip surrounding the 2011 Tohoku-oki earthquake rupture. Earth and Planetary Science Letters 374, 81-91.

Webb, F.H., Zumberge, J.F., 1993. An introduction to the GIPSY-OASIS-II. JPL Publ. D-11088. Wessel, P., Smith, W.H.F., Scharroo, R., Luis, J., Wobbe, F., 2013. Generic Mapping Tools: Improved Version Released. Eos Transactions American Geophysical Union 94, 409-410.

Xu, K., Liu, J., Liu, X., Liu, J., Zhao, F., 2020. Multi-scale crustal deformation around the southeastern margin of the Tibetan Plateau from GNSS observations. Geophysical Journal International.

$\mathrm{Xu}, \mathrm{K} ., \mathrm{Wu}, \mathrm{J} ., 2014$. Detection of abnormal stations for rigid plate and acquisition of motion parameters based on robust estimation. Journal of Geodesy and Geodynamics. Journal of Geodesy \& Geodynamics 34, 95-99.

Xu, K.K., Gan, W.J., Wu, J.C., 2019. Pre-seismic deformation detected from regional GNSS observation network: A case study of the 2013 Lushan, eastern Tibetan Plateau (China), Ms 7.0 earthquake. Journal of Asian Earth Sciences 180, 103859.

$\mathrm{Xu}, \mathrm{K} . K ., \mathrm{Wu}$, J.C., Wu, W.W., 2015. Detection of transient aseismic slip signals from GNSS spatial-temporal data. Chinese Journal of Geophysics 58, 2330-2338. 
Figures

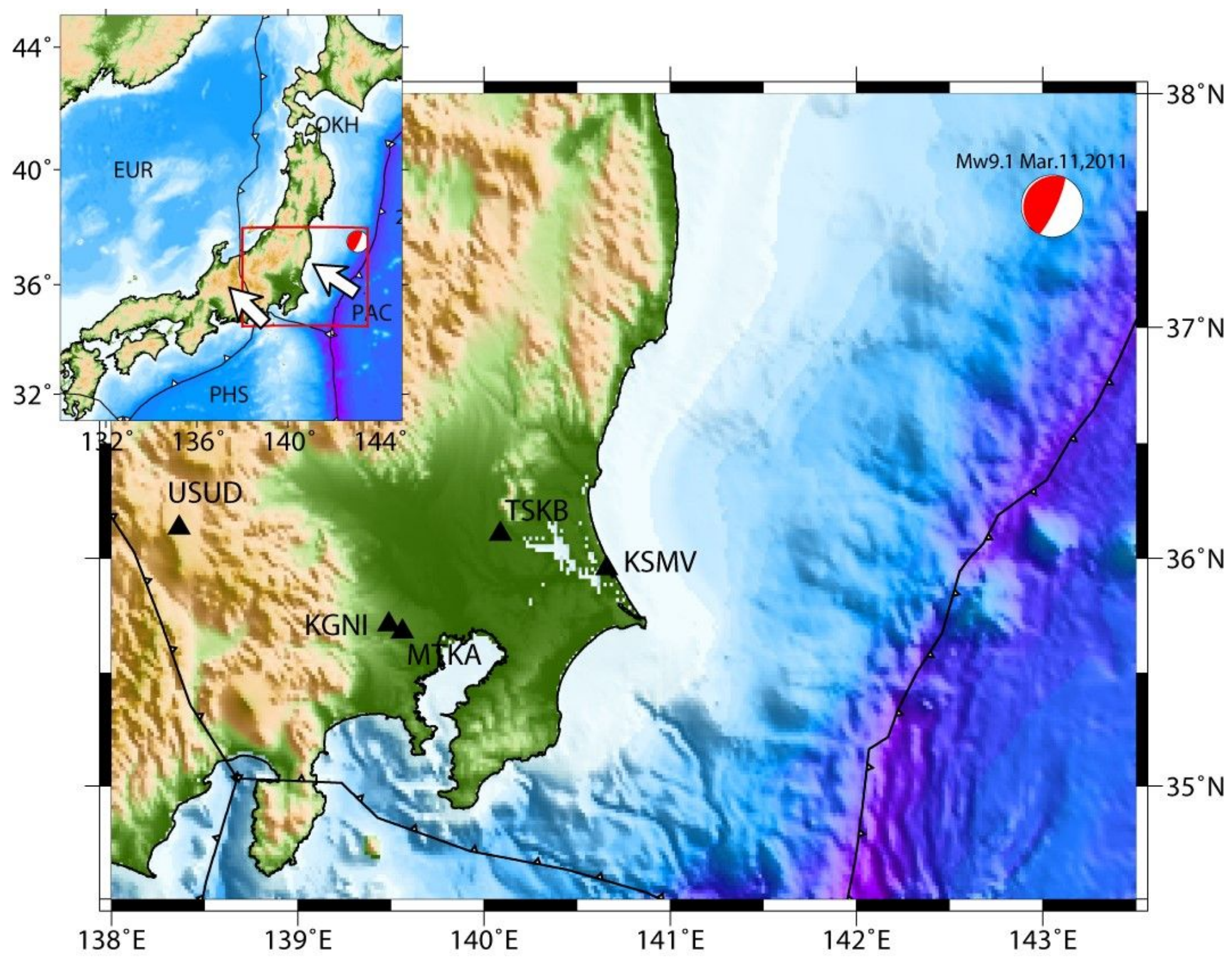

Figure 1

Tectonic settings of the Japanese islands. The study area is depicted in the inset map. EUR, PHS, PAC, and OHK denote Eurasian, Philippine Sea, Pacific and Okhotsk plate, respectively. Beach balls denote GCMT of the earthquake. White arrows indicate the relative plate motion directions. EUR: Eurasian plate, OKH: Okhotsk plate, PHS: Philippine Sea plate, and PAC: Pacific plate. Note: The designations employed and the presentation of the material on this map do not imply the expression of any opinion whatsoever on the part of Research Square concerning the legal status of any country, territory, city or area or of its authorities, or concerning the delimitation of its frontiers or boundaries. This map has been provided by the authors. 

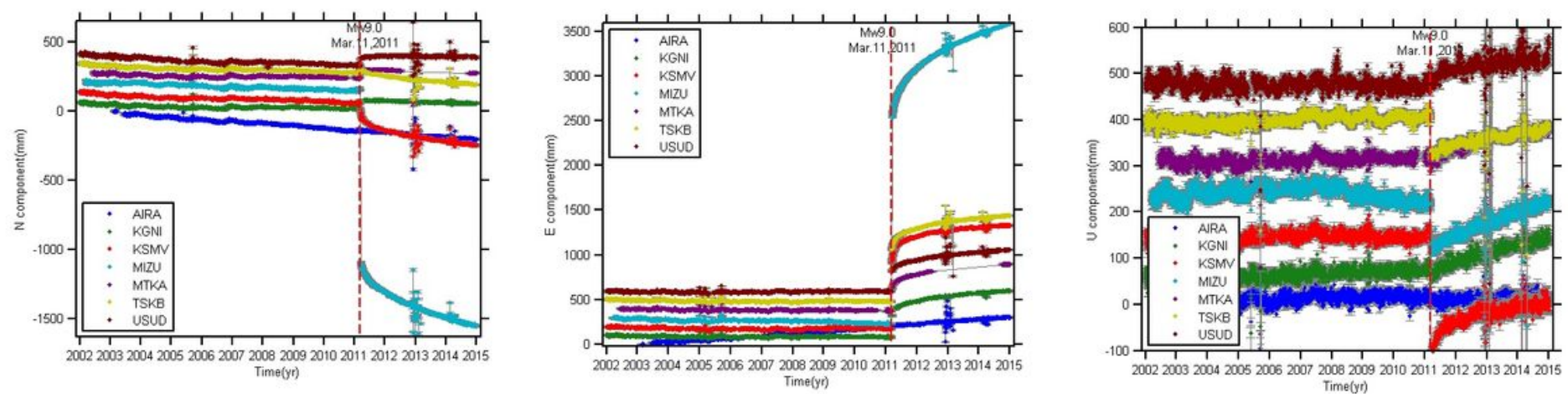

Figure 2

Raw time series of variations in daily site coordinates for the period from 2002 to 2014 . The North component, East component and Up components are shown from left to right.
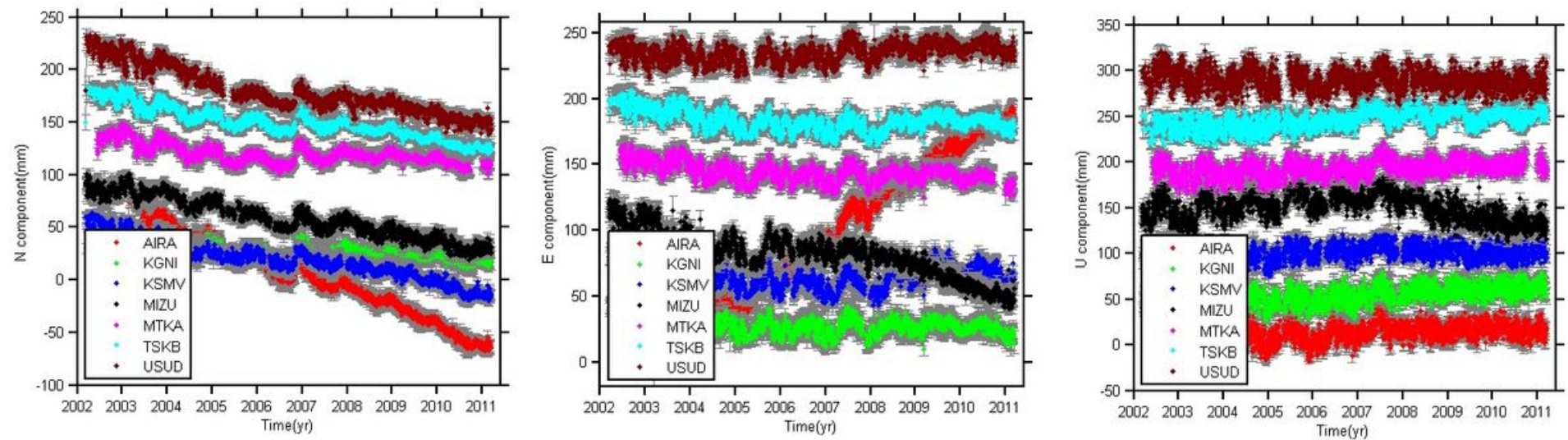

Figure 3

Pre-seismic GPS displacement time series over the period of Feb. 12th, 2002-Mar. 10th, 2011 in N,E,U component from left to right

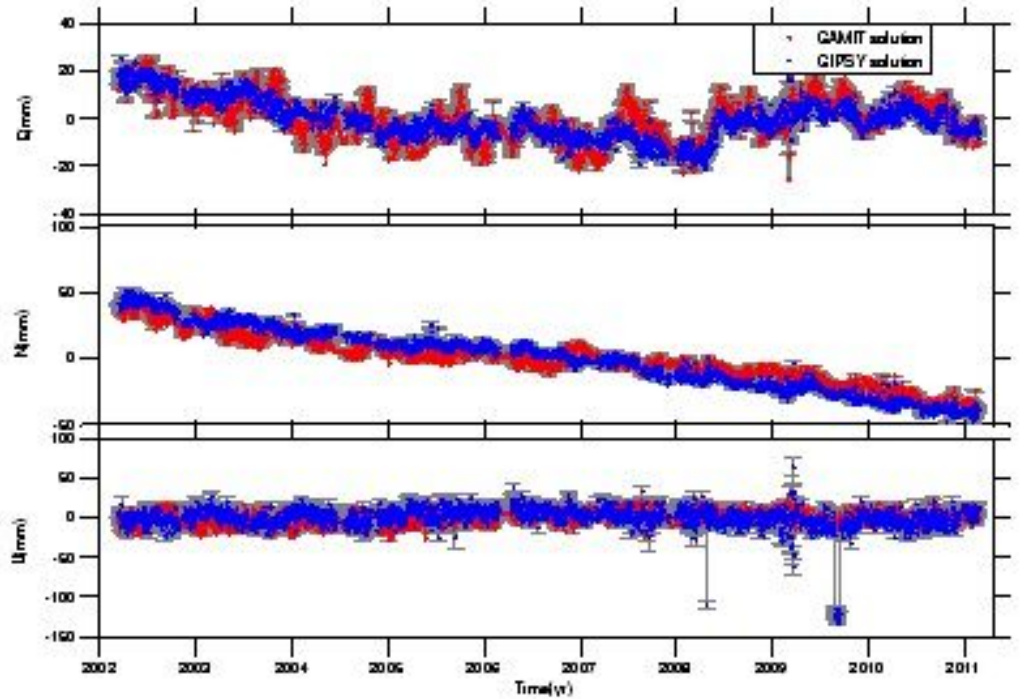


Figure 4

The comparison between the time series of daily site coordinates at KSMV station calculated by GAMIT10.4 and GIPSY/OASIS-II.
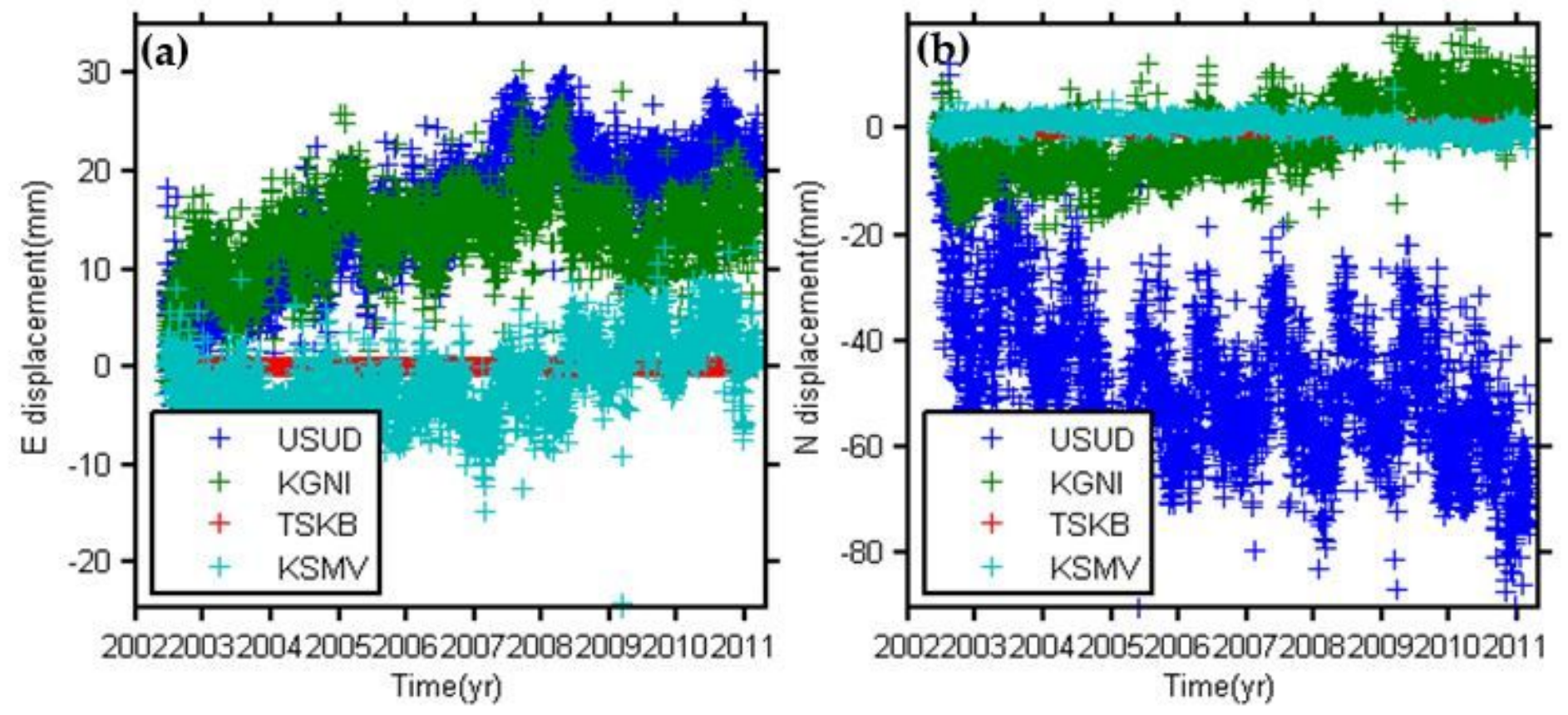

Figure 5

Displacement time series in $\mathrm{E}$ component(a) and $\mathrm{N}$ component(b) by similarity transformation.
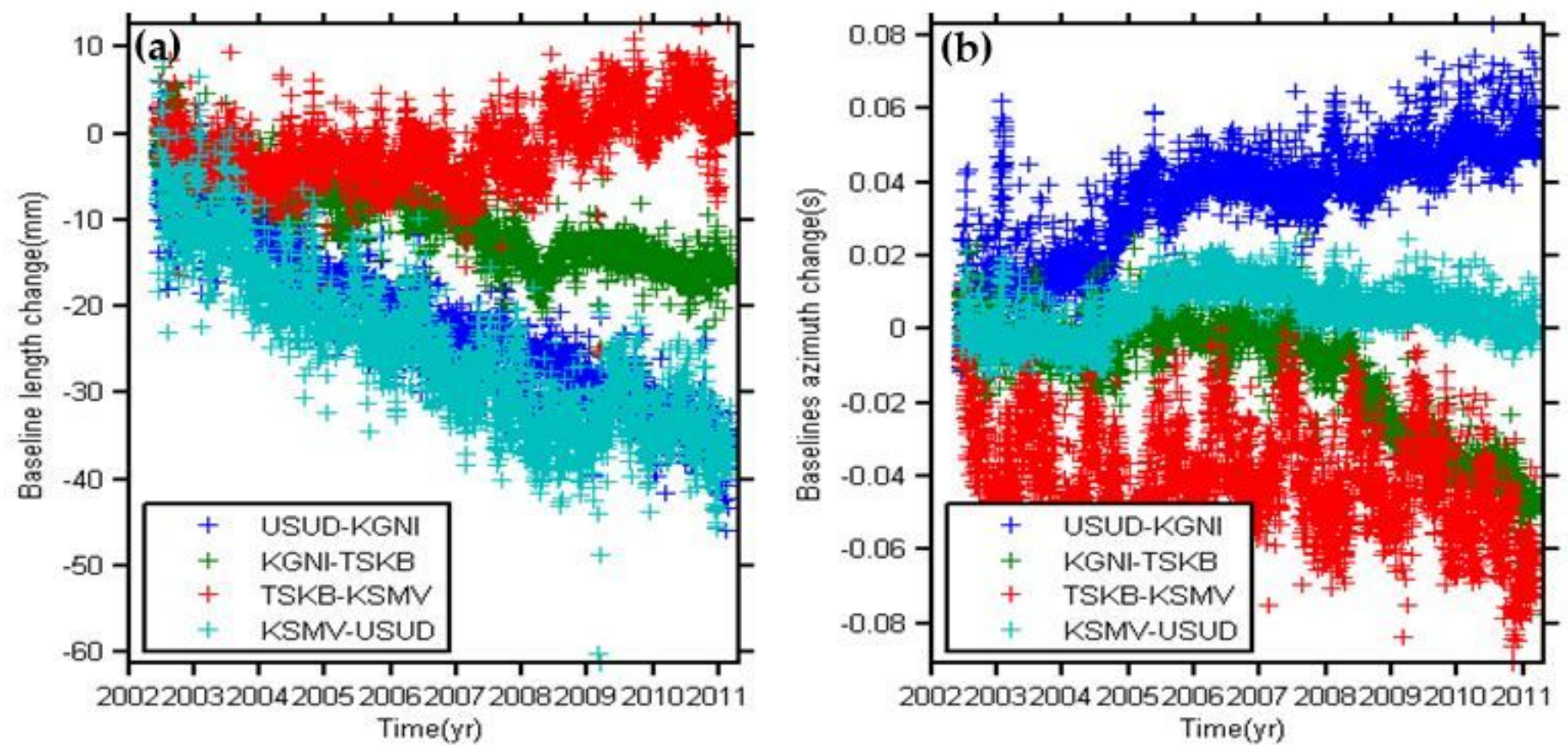

Figure 6 
Time series of variations in daily GPS baseline length(a) and azimuth (b) prior to the earthquake.


\section{Figure 7}

Daily GPS Site Coordinate time series at representative stations, corrected for the secular velocities, seasonal variation and outfield value. The North component, East component and Up components are shown from left to right. 


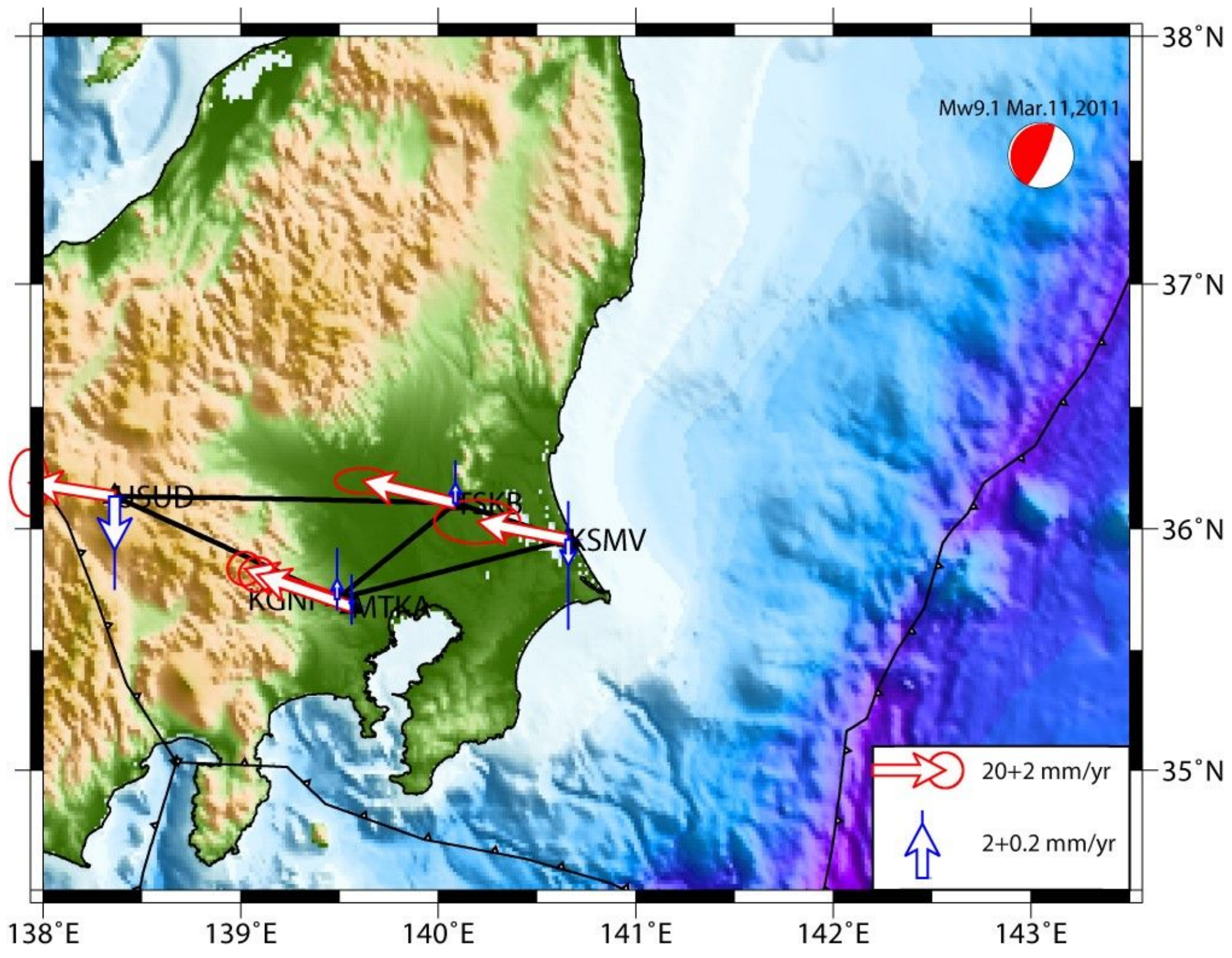

Figure 8

GPS velocity of 5 sites with respect to Eurasian plate. Each velocity arrow originates at the location of the site and points to its motion direction. Error ellipses represent 95\% confidence level. Note: The designations employed and the presentation of the material on this map do not imply the expression of any opinion whatsoever on the part of Research Square concerning the legal status of any country, territory, city or area or of its authorities, or concerning the delimitation of its frontiers or boundaries. This map has been provided by the authors. 


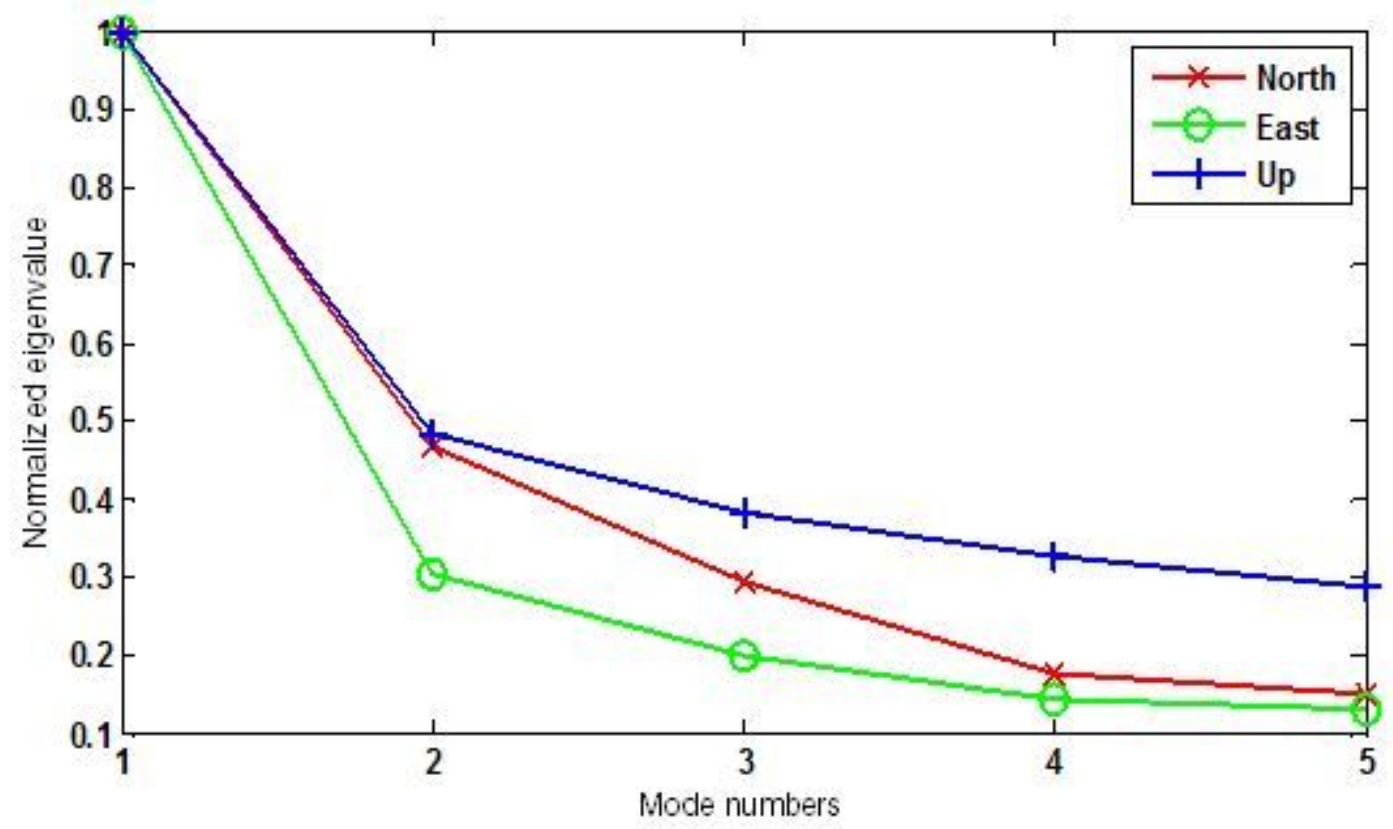

Figure 9

First 5 eigenvalues normalized by the highest one in N, E, U components
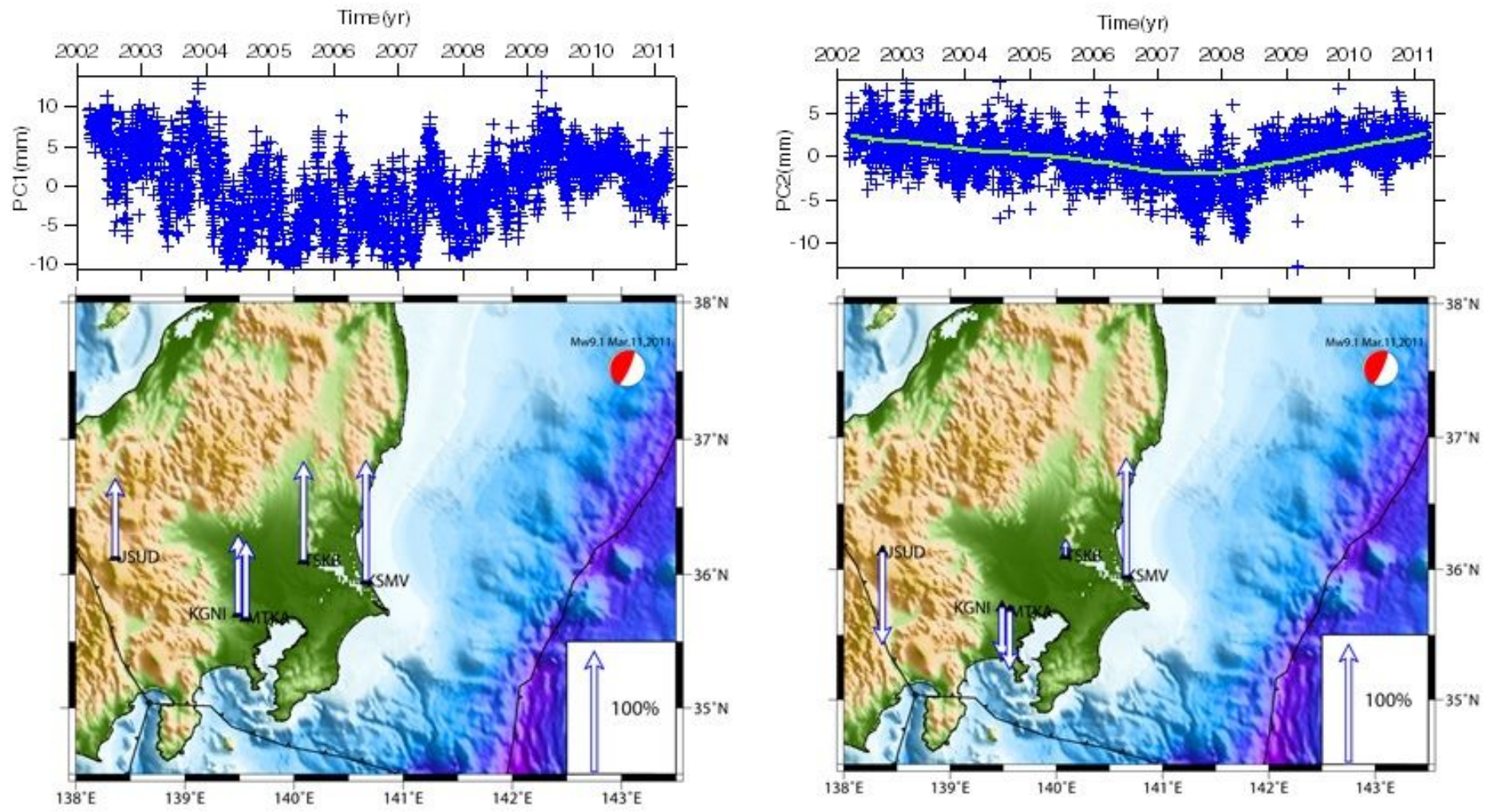

Figure 10 
East component of PCA solution. (left) (top) First scaled PC and (bottom) its normalized spatial eigenvectors. The arrows represent the element values of the normalized eigenvectors (not the displacement directions). The upward and downward arrows represent positive and negative responses to the scaled PC, respectively. (right) (top) Second scaled PC and (bottom) its normalized spatial eigenvectors. Solid green curve represent the fit to the data by Gaussian smooth filter.
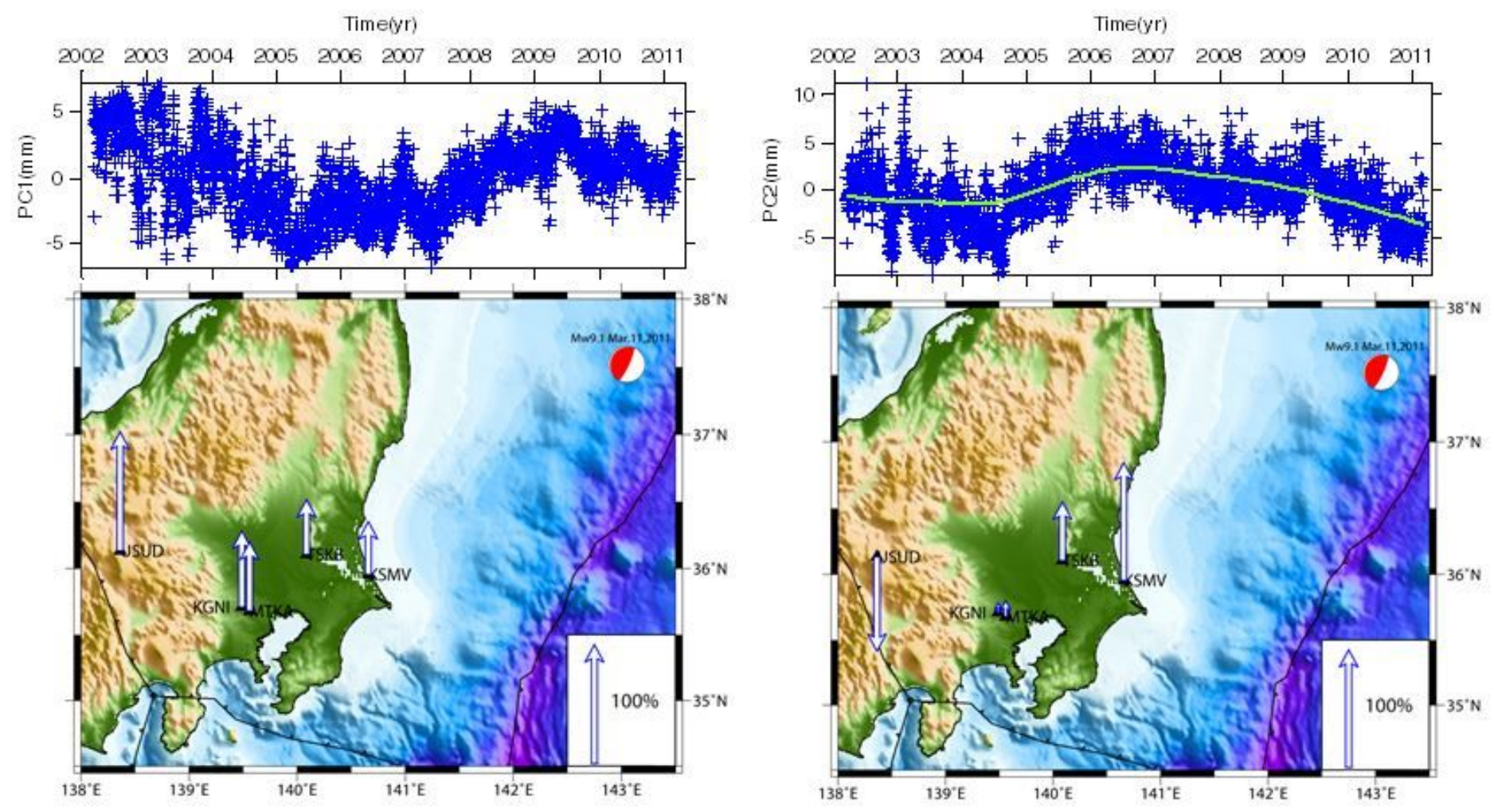

Figure 11

North component of PCA solution. (left) (top) First scaled PC and (bottom) its normalized spatial eigenvectors. (right) (top) Second scaled PC and (bottom) its normalized spatial eigenvectors. The arrows and solid green curve are defined as in Fig.10 
Time(y r)

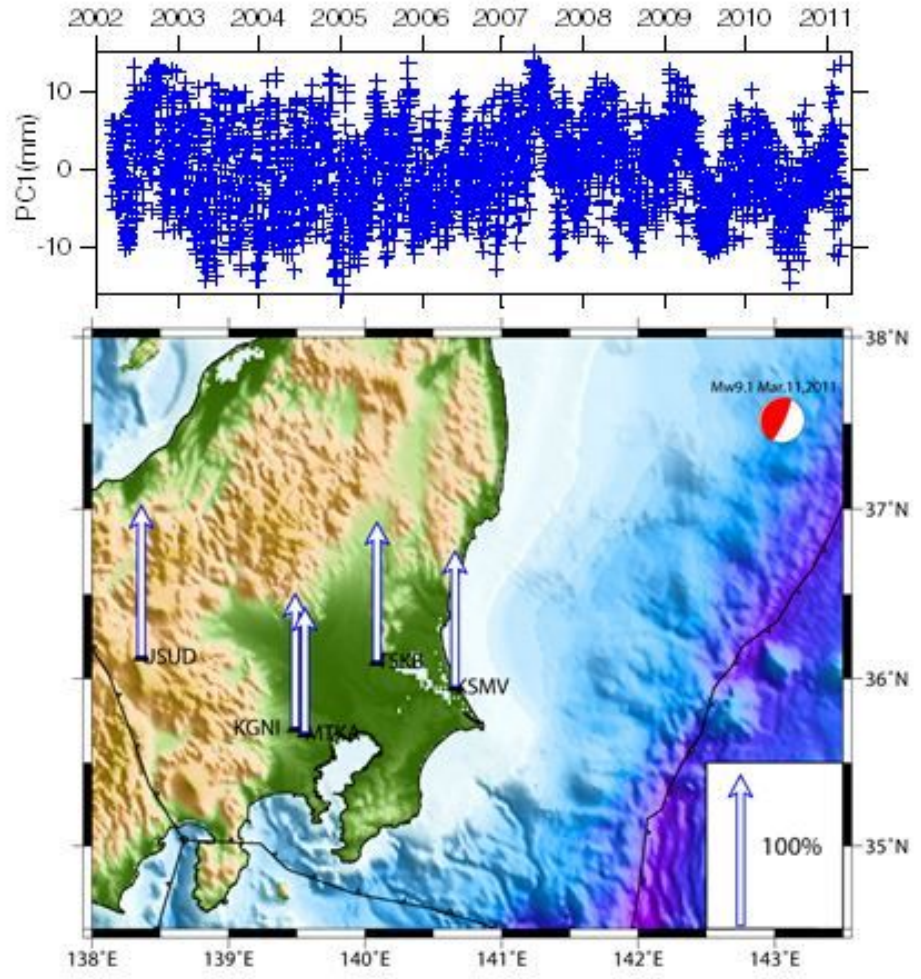

Time(yr)
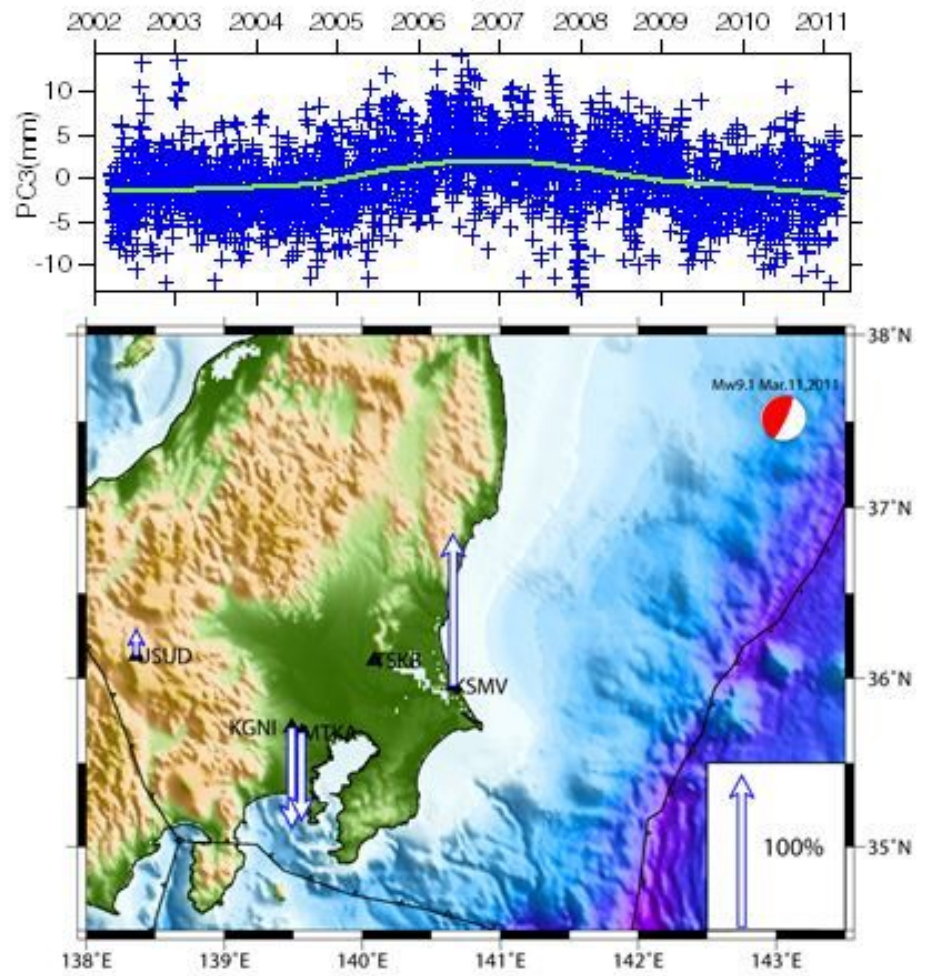

Figure 12

Vertical component of PCA solution. (left) (top) First scaled PC and (bottom) its normalized spatial eigenvectors. (right) (top) Third scaled PC and (bottom) its normalized spatial eigenvectors. The arrows and solid green curve are defined as in Fig.10.
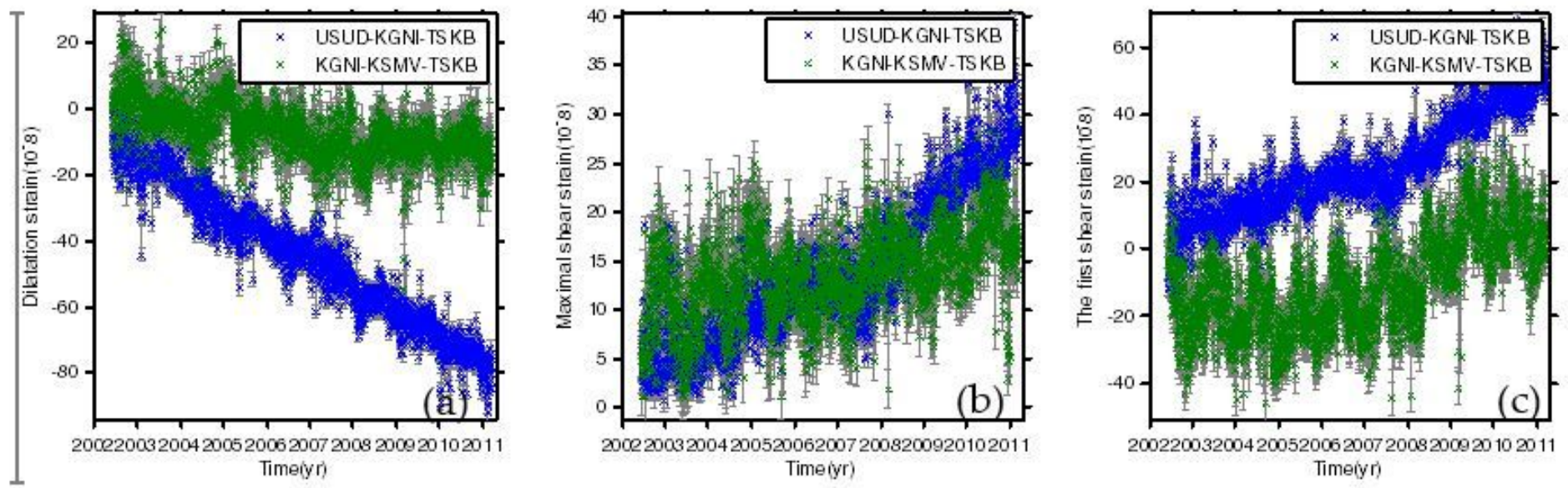

Figure 13

Dilatation strain(a), maximum shear strain(b), and first shear strain array(c) of two regions TSKB-KSMVMIZU and USUD-TSKB-MIZU drawn in Fig.8. 

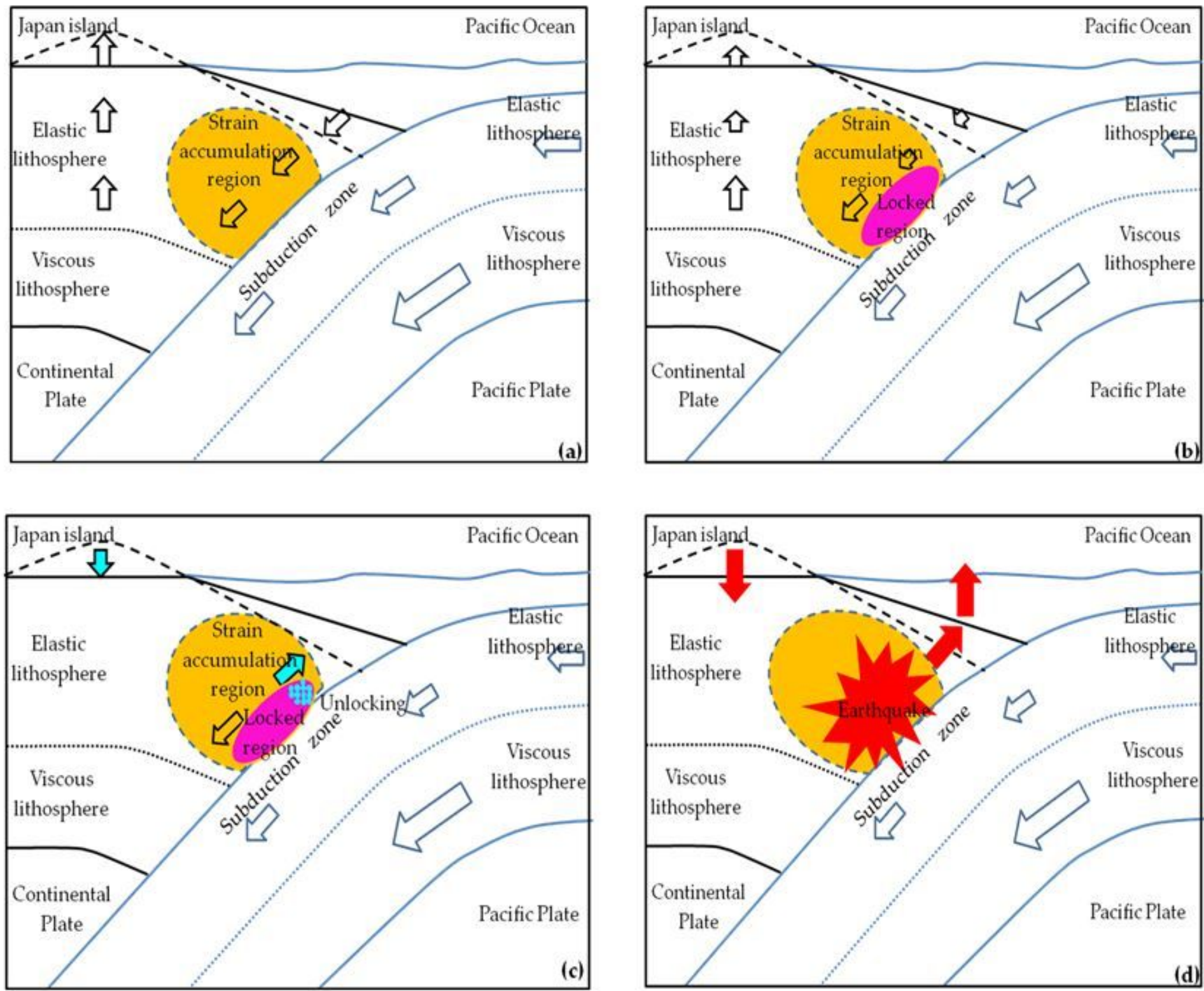

\section{Figure 14}

Seismogenic model in plate subduction region.(a) the stable linear strain accumulation stage.(b) the formation stage of the local locked area. (c) local decoupling stage. (d)great rupture and strain release stage(occurrence of great earthquake)

\section{Supplementary Files}

This is a list of supplementary files associated with this preprint. Click to download.

- GraphicalAbstract.png 